\title{
Characterizing migration behaviour of adult Fraser River sockeye salmon \\ (Oncorhynchus nerka) during coastal and estuarine passage using acceleration transmitters
}

\author{
By \\ Samantha M. Wilson \\ B.Sc., Carleton University, 2011
}

A thesis submitted to the Faculty of Graduate Studies and Research in partial fulfillment of the requirements for the degree of

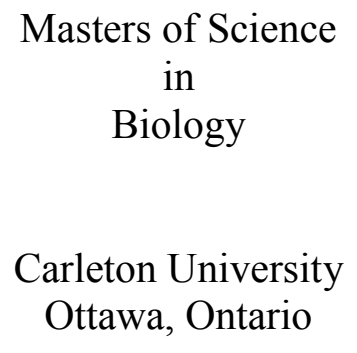

(C)2013, Samantha M. Wilson 


\section{Dedication}

To Dad for instilling in me the value of conservation and introducing me to fishing and the natural world, to Mom for ingraining in me the value of education, and to Sarah, for teaching me the meaning of perseverance. Thank you to my friends in the Hinch and Cooke labs, both past and present, for sharing experience, for support and for all the amazing memories. To Scott for your support and guidance (and shelter!) over the

past three years. To Steve for all of the amazing opportunities and experiences, all of which have helped foster a passion for research which will fuel the years to come. 


\begin{abstract}
Though behaviour during the reproductive migration of Pacific salmon (Oncorhynchus spp.) has been studied during upriver migrations, equivalent information for coastal marine migrations has been difficult to obtain. Newly developed acoustic acceleration transmitters provided a possible tool for the study of swim speed and depth of salmon in both marine and freshwater. In Chapter 2, I used swim tunnel respirometry and demonstrated that these transmitters could be used to predict swim speed and energy use from acceleration output. In Chapter 3, I tagged ocean migrating sockeye salmon $(O$. nerka) with these transmitters and tracked swim speed and depth as they crossed several acoustic receiver lines in coastal waters and the lower Fraser River. Using statistical models developed in Chapter 2, I examined how environmental factors influenced swim speed, and depth. These are the highest temporal and spatial resolution data collected on coastal migration behaviour of adult sockeye salmon, to date.
\end{abstract}




\section{Acknowledgments}

First I would like to thank my supervisors, S. Cooke and S. Hinch, for providing me with constant support, feedback and countless amazing opportunities throughout the completion of this thesis. I would also like to thank the members of the Hinch and Cooke labs C. Middleton C. Whitney, A. Lotto, G. Raby, N. Sopinka, and K. Robinson for assistance with fish collection and transport. I especially thank E. Eliason for instruction and assistance with swim tunnel respirometers and M. Drenner for technical assistance throughout receiver deployment. I would also like to thank the Chehalis First Nations fishers for collection of salmon from the Harrison River and the Bon Chovy crew for their assistance throughout collection of fish in the Fraser River estuary. I would like to thank M. Griswold and P. Griswold for fish collection in Johnstone Strait and assistance in Seymour Narrows receiver deployment. I would also like to thank the members of the DFO Environmental Watch Program, especially D.A. McKay for help with tagging fish in Johnstone Strait. I thank the staff at DFO Cultus Lake, especially B. Smith for logistical support. Finally, I would like to thank all my co-authors, especially E. Martins for assistance with statistical analysis. My work was supported through the Ocean Tracking Network Canada, through funding from the Natural Sciences and Engineering Research Council of Canada (NSERC) and the Canada Foundation for Innovation (CFI). Additional support was provided from NSERC Discovery Grants to S. Hinch, S. Cooke and A. Farrell. I received stipend support through NSERC USRA and CGA-M programs as well as from the Ontario Graduate Scholarship program. 


\section{Co-Authorship}

Chapter 2: Calibrating acoustic acceleration transmitters for estimating energy use by wild adult Pacific salmon. S. M. Wilson, S. G. Hinch, E. J. Eliason, A. P. Farrell, and S. J. Cooke

While this study is my own, the research was undertaken as part of a collaborative effort and each co-author played a valuable role in its completion. The project was conceived by Wilson, Hinch, and Cooke. Fieldwork was completed by Wilson and Eliason. All computer and data analysis was conducted by Wilson. Data were interpreted by all authors. All writing was conducted by Wilson. All co-authors provided comments and feedback on the manuscript.

Wilson, S. M., Hinch S. G., Eliason, E. J., Farrell, A. P., Cooke, S. J. 2013. Calibrating acoustic acceleration transmitters for estimating energy use by wild adult Pacific salmon. Comp. Bioc. Phys. A - 164(3): 491-498.

\section{Chapter 3: Coastal marine and in-river migration behaviour of adult} sockeye salmon en route to spawning grounds. S. M. Wilson, S. G. Hinch, S. M. Drenner, E. G. Martins, N. B. Furey, D. A. Patterson, D.W. Welch and S. J. Cooke

While this study is my own, the research was undertaken as part of a collaborative effort and each co-author played a valuable role in its completion. The project was conceived by Wilson, Hinch, and Cooke. Fieldwork was completed by Wilson and Drenner. All computer and data analysis was conducted by Wilson, Furey and Martins. Data were interpreted by Wilson and Martins. All writing was conducted by Wilson. All 
co-authors provided comments and feedback on the manuscript. This manuscript has been submitted for publication in Marine Ecology Progress Series. 


\section{Table of Contents}

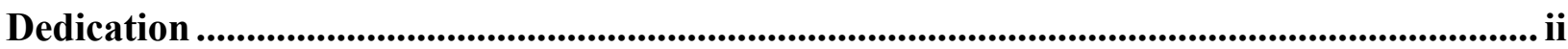

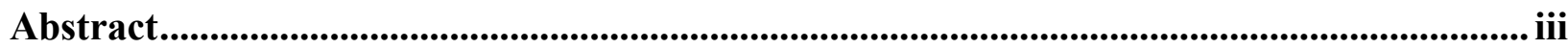

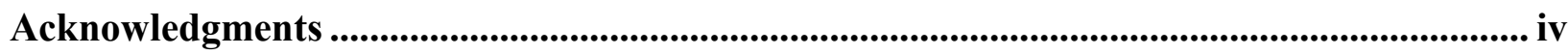

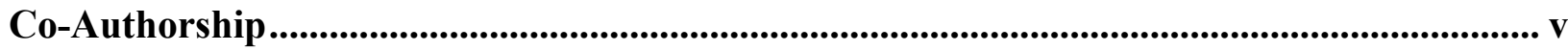

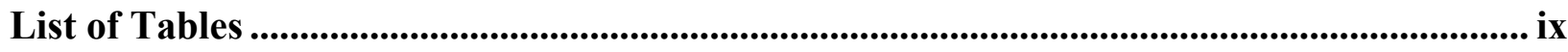

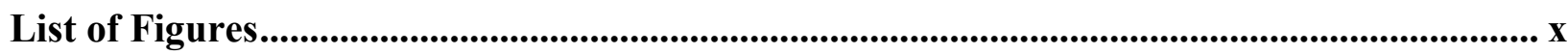

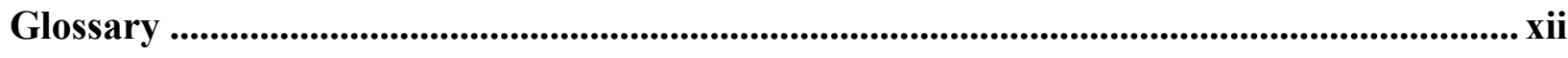

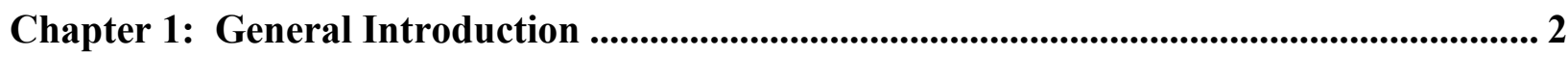

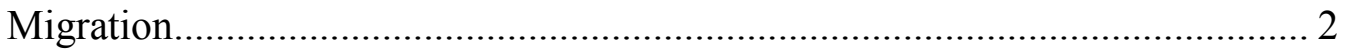

Locomotion and Swim Performance in Fish .............................................. 4

Estimating Swim Speed in Fish ......................................................... 6

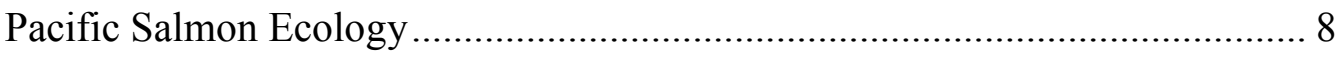

Research Objectives...................................................................... 12

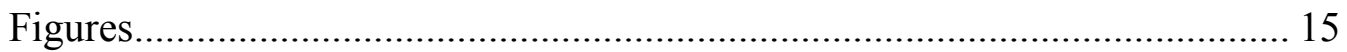

Chapter 2: Calibrating acoustic acceleration transmitters for estimating energy use by wild adult Pacific salmon ........................................................................................................ 16

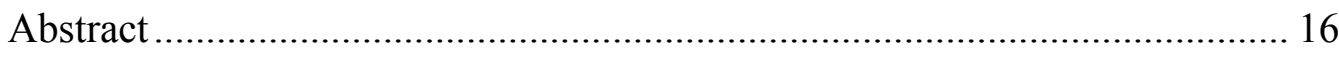

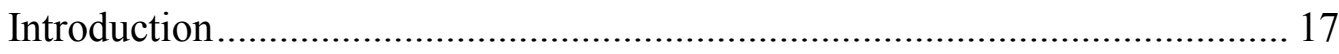

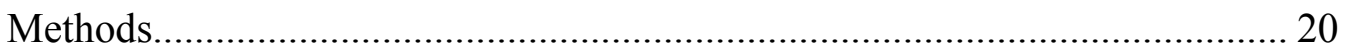

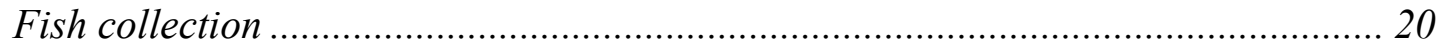

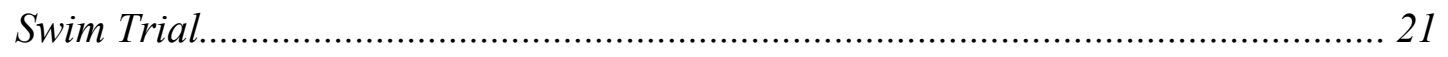

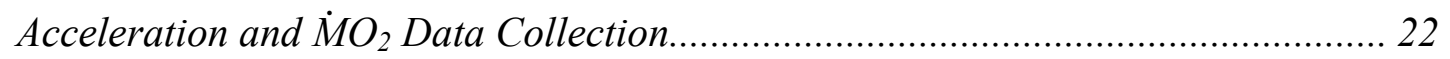

Field Assessment of Acceleration Transmitter Performance .................................. 24 


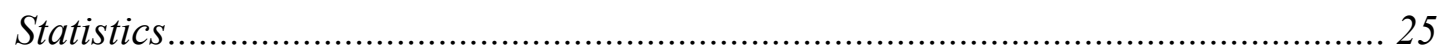

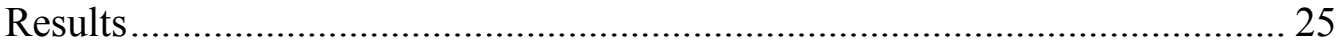

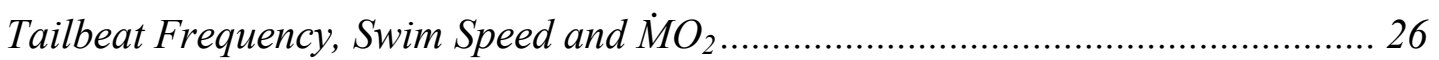

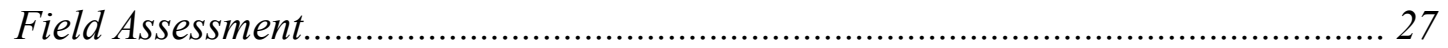

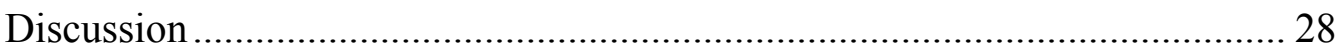

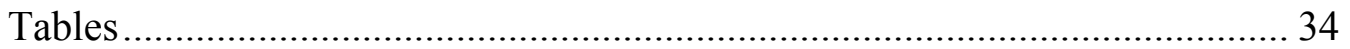

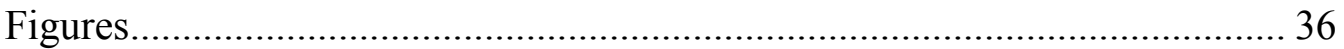

Chapter 3: Coastal marine and in-river migration behaviour of adult sockeye salmon en route to spawning grounds................................................................................................ 41

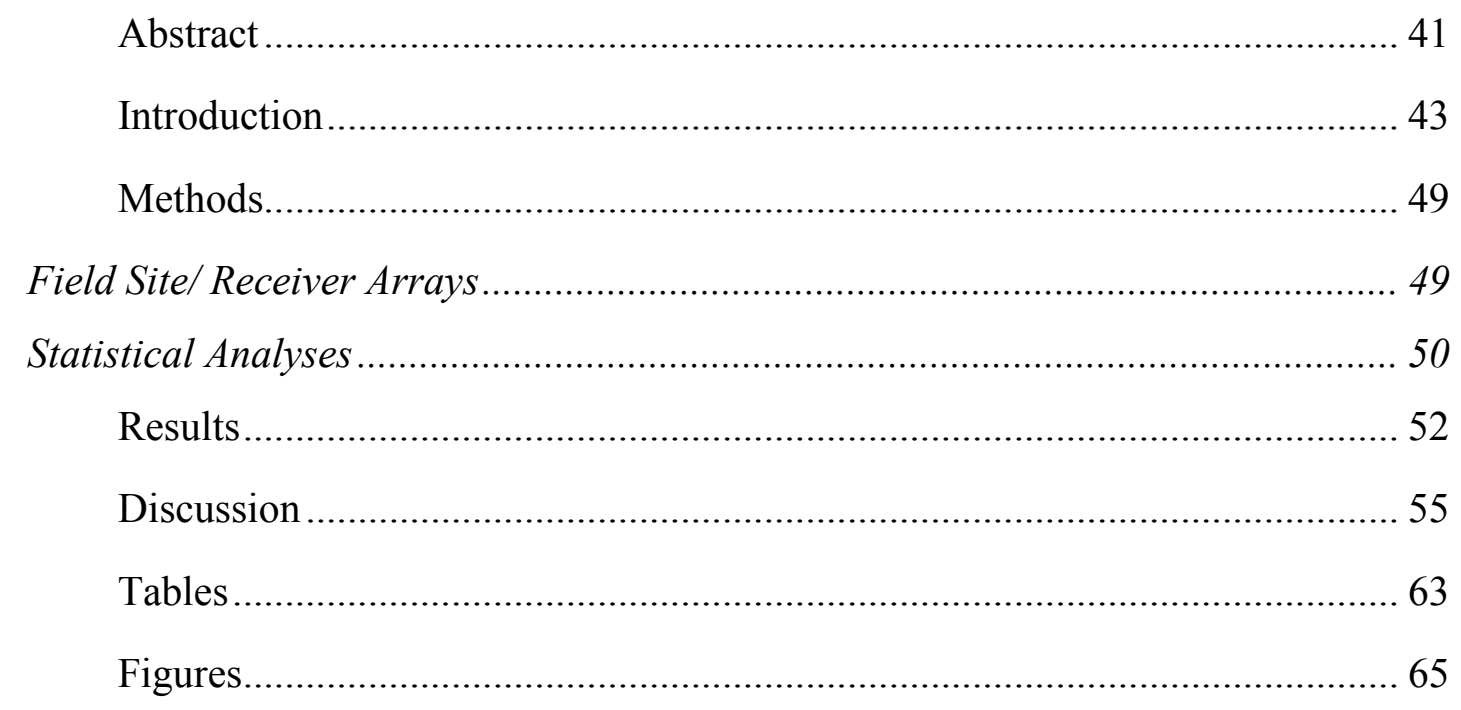

Chapter 4: General Discussion ............................................................................................... 71

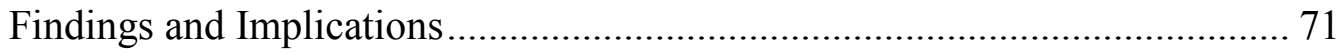

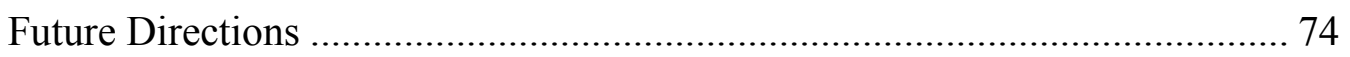

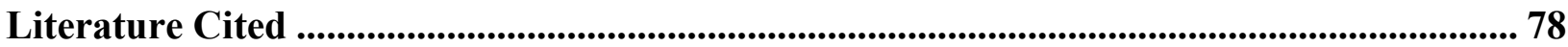


List of Tables

Table 2-1. Linear regressions for TBF and acceleration at $14{ }^{\circ} \mathrm{C}$ for each of the nine fish tagged with acceleration transmitters.

Table 2-2. Significance of variables and variable interactions for acceleration and TBF, acceleration and swim speed and $\dot{\mathrm{MO}}_{2}$ and acceleration relationships for the nine fish

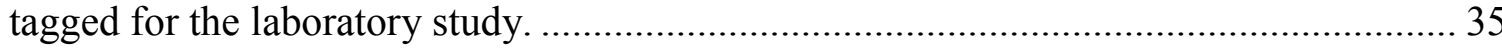

Table 3-1. Acoustic acceleration transmitters deployed in sockeye salmon and migratory

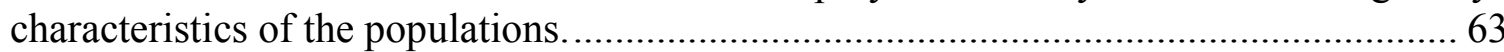

Table 3-2. Summary of swimming behaviour for tagged sockeye salmon................... 64 


\section{List of Figures}

Figure 1-1. Tri-axial acoustic acceleration transmitter A) Photograph of V13AP acceleration transmitter, potted in V16 case B) Dynamic body acceleration ( $\mathrm{g}$ ) of a steady swimming Lemon shark (Negaprion brevirostris), split into three individual axes- sway, heave and surge (adapted from Shepard et al., 2008).

Figure 2-1. Relationships between acceleration and TBF (left column), acceleration and swim speed (center column), and $\dot{\mathrm{MO}}{ }_{2}$ and acceleration ( $=\mathrm{m} \mathrm{s}^{2}$; right column) for individual sockeye salmon at $14^{\circ} \mathrm{C}$. Each row represents relationships for a single fish. Dotted lines represent $95 \%$ confidence intervals.

Figure 2-2. The relationship between TBF and acceleration at $14^{\circ} \mathrm{C}$ for $\mathrm{A}$ ) three adult sockeye tagged with the same V9A-2H acceleration transmitter and $\mathrm{B}$ ) six individual adult sockeye salmon gastric tagged with six unique V9A-2H acceleration transmitters. Each line represents the relationship between TBF and acceleration for a single fish. Each symbol represents an individual sockeye salmon. (Open symbols = females; closed symbols $=$ males $)$.

Figure 2-3. Relationship between $\mathrm{MO}_{2}$ and acceleration at A) $\left.\left.12^{\circ} \mathrm{C}, \mathrm{B}\right) 14^{\circ} \mathrm{C}, \mathrm{C}\right) 16^{\circ} \mathrm{C}$, D) $18^{\circ} \mathrm{C}$, E) $20^{\circ} \mathrm{C}$ and F) $22^{\circ} \mathrm{C}$. Each line represents the relationship between $\mathrm{MO}_{2}$ and acceleration for all fish swam at a given temperature. Each symbol represents and individual sockeye salmon. (Open symbols = females; closed symbols = males). 38

Figure 2-4. Relationship between acceleration and swim speed at $14{ }^{\circ} \mathrm{C}$. Each line represents the relationship between acceleration and swim speed for all fish. Each symbol represents and individual sockeye salmon. (Open symbols = females; closed symbols = males). Dotted lines represent 95\% confidence intervals.

Figure 2-5. Percent of detections at a range of swim speeds for three sockeye salmon released in the Fraser River estuary. Tag IDs were used to identify the proportion of detections from a given fish at each swim speed. Swim speeds determined using relationship between acceleration and swim speed.

Figure 3-1. Map of acoustic receiver arrays throughout SOG and lower Fraser River. (1Seymour Narrows, 2-Northern Strait of Georgia (NSOG), 3-River Entrance, 4-In River). Sockeye salmon were captured by trolling and released in Rock Bay.

Figure 3-2. Behavioural trait characterized for each migration difficulty index at each receiver array; A) swim speed B) timing to first detection (release to 1, 1-2, etc). Easy migrations are represented in black, intermediate in dark grey and difficult in light grey. Error bars represent SEM. Letters represent significant differences between migration difficulty groups $\alpha=0.05$.

Figure 3-3. Comparison between A) ground speed and swim speed calculated using acceleration transmitters and B) repeatability of swim speeds between Seymour Narrows and NSOG, NSOG and river entrance and river entrance and in-river arrays. Ground 
speed represented in black and swim speed in grey. Asterisk represents significance of $p<$ 0.05 .

Figure 3-4. Trace of swim speed for three individual sockeye salmon at A) Seymour Narrows, B) NSOG, C) River Entrance, and D) In River. Each line type represents a different individual...

Figure 3-5. Depth of swimming for each migration index at each receiver array (see Fig. 4). Easy migrations are represented in black, intermediate in dark grey and difficult in light grey. Error bars represent SEM. Letters represent significant differences between migration difficulty groups $\alpha=0.05$.

Figure 3-6. Trace of depth of swimming for three individual sockeye salmon at A) Seymour Narrows, B) NSOG, C) River Entrance, and D) In River. Each line type represents a different individual. 


\section{Glossary}

AICc: Corrected Akaike information criterion

BL: Body length

COT: Cost of transport

DFO: Fisheries and Oceans Canada

EMG: Electromyogram

ECG: Electrocardiogram

FL: Fork length

ID: Identity

$\dot{\mathrm{MO}_{2}}$ : Rate of oxygen consumption

MS222: Tricaine methanesulphonate

ODBA: Overall dynamic body acceleration

PDBA: Partial dynamic body acceleration

PSC: Pacific Salmon Commission

RMS: Root mean square

SE: Standard error

TBF: Tailbeat frequency

$\mathrm{U}_{\text {crit }}:$ Critical swimming speed 


\section{Chapter 1: General Introduction}

\section{Migration}

Movement can be characterised into two broad behaviours: movements associated with home ranges and resources (i.e., station keeping, territorial behaviour, ranging) and those associated with migration (Dingle, 1996). Behavioural traits are used to differentiate between movement types where migrating organisms display a combination of behaviours independent of taxa, size of organism or method of locomotion. Migrants will 1) move persistently in a specific direction from one distinct habitat to another, 2) move in a more directed manner compared to station-keeping behaviour, 3) have distinct departure and arrival behaviours, 4) move undistracted by stimuli that would stop them while station keeping and ranging 5) reallocate energy towards movement (Dingle, 1996). For the purpose of this thesis, migration is defined as the persistent, synchronous, directional, long-distance movement of a number of individuals of the same species between distinct environments (Endler, 1977; Dingle, 1996).

Although 'classic' migrations occur in a cyclic pattern, where individuals migrate between one or more sites to exploit temporary resources (i.e., Artic tern (Sterna paeadisaea), mule deer (Odocoileus virginianus), monarch butterfly (Danaus plexippus)) and often involve migration from feeding areas and assembly at sites of high quality breeding and rearing habitat, not all migrations can be spatially defined. Migration type has, therefore, been described in several ways: by organism (i.e., obligate, facultative, 
partial, differential), time (i.e., seasonal, irruptive), medium (i.e., diadromic, drift) and spatial patterns (i.e., to-and-fro, round trip, one-way, altitudinal, nomadic) (See review by Dingle \& Drake, 2007). Apart from flight and migrations over land, these migrations may also take place in seawater and/or freshwater over various taxa including mammals, reptiles and fish. There are several types of fish migrations which are defined based on the migration origin, destination and purpose. Oceanonadromous migrations take place solely within the ocean whereas migrations that occur solely in freshwater are classified as either potamodromous, which occur between rivers and lakes or limnodromous which occur wholly in lakes. Migrations that occur between freshwater and seawater are called diadromous, and can involve spawning migrations from seawater to freshwater (anadromous), and spawning migrations from freshwater to seawater (catadromous). Non-reproductive diadromous migrations are called amphidromous (McDowall, 1988).

The evolutionary basis for migration is that fitness benefits and costs of inhabiting certain locations can change across life history stages. As a result, migrations usually accompany key life-history transitions and can confer fitness advantages through pre-emptive relocation to a habitat that may be more suited to the requirements of the specific life history stage (Dingle, 1980). For example, an area that is well protected may be most suitable for avoiding predation during juvenile stages, but a habitat rich in resources is required to maximize growth in a later stage. In another example, seasonal fluctuations may result in habitat deterioration and rather than waiting until habitat quality has seriously declined, pre-emptive departure (usually signalled by photoperiod) enables the organism to move before resources run out, and migration may be impossible. 
In such cases migration is favoured over station keeping and may be an adaptive strategy in extremely variable habitats (Dingle \& Drake, 2007).

There is a strong selective pressure towards appropriate allocation of energy prior to migration, especially in the case of migration for the purpose of reproduction, where energy must be divided between somatic maintenance, movement and gamete production (Calow, 1985). This is especially true in the case of capital breeders which fuel migrations solely through endogenous energy reserves, and depletion of energy reserves may lead to an abandonment of that reproductive attempt, or death (Jönsson, 1997), as well as semelparous species (reproduction once), where failure to reproduce results in zero lifetime fitness. Changes from historic norms, such as changes in temperature, destruction of critical stopover habitat, and in the case of aquatic migration, alteration of flow regimes such as installation of dams, can influence energy use, condition and survival of migrants. In particular, migratory game-fish may be at greater risk of endangerment, as fishing pressure is often highest at critical points in life history (e.g. when diadromous fish aggregate in estuaries; McDowall, 1999; Donaldson et al., 2011). Thus understanding overall migration behaviour and how migration behaviour and environmental conditions influence energy requirements is important to understanding the ecology of migrating species, and conservation efforts (McDowall, 1999).

\section{Locomotion and Swim Performance in Fish}

Fish can swim over a large range of swim speeds and acceleration rates, however, a single locomotor pattern is not efficient across all ranges. Therefore fish use different gaits in each small portion of their range (Webb, 1995). Gaits may be as simple 
as using paired fins to generate negative lift, as with holding, or as complex as burst and coast swimming. Gaits are defined by the propulsive system (i.e., fins used) and muscle system used. Median and paired fin (MPF) propulsors are used at low swim speeds, and are succeeded by body/caudal fin swimming. Body/caudal fin swimming is powered by slow oxidative muscle at steady swimming speeds and fast glycolytic muscle during sprints (Webb, 1995). Not all fish will perform equally well in all gaits, but will often be specialized for a few gaits, dependent on habitat (i.e., fast flowing water of streams, compared to lakes). Specialized fish tend to have locomotor functional morphologies, esociform fish are specialized accelerators (e.g., northern pike, Esox lucius), thunniform fish specialize in cruising (e.g., Atlantic bluefin tuna, Thunnus thynnus), while chaetodontiform fish are manoeuvres (e.g., blueblotch butterflyfish, Chaetodon plebeius; Webb, 1984).

Fish that are body/caudal fin and slow oxidative gait specialists tend to be located closer to esociform and thunniform morphologies on the functional morphology plane. This body form decreases drag during cruising or accelerating, ultimately allowing for more efficient energy use, where cost of transport (COT) is decreased at higher swim speeds, compared to other morphologies (Brett, 1995). COT is the ratio of power input (metabolic rate) to power output (unit body weight by unit distance) and is inversely related to the efficiency of the transport process (Tucker, 1970). The relationship between COT and swim speed is U-shaped where COT is high at low swim speeds when energy is used for standard metabolic rate, and at high speeds when cost of locomotion is high (drag increases). Net COT, or the power input required above standard metabolic rate is 
then linearly related to swim speed where COT increases as locomotor costs increase. Minimum COT transport varies depending on body weight, morphology and type of locomotion (Tucker, 1970). Body/caudal fin -slow oxidative and body/caudal fin -fast glycolytic gait specialists may use behavioural strategies to help reduce COT, such as burst-and-coast swimming. During coasts drag is three to five times lower than in powered swimming and can result in an energy saving of up to $60 \%$ (reviewed in Brett, 1995). Thus in addition to functional morphologies, different energy-saving locomotor behaviours can be used to lower COT.

\section{Estimating Swim Speed in Fish}

A number of methods can be used to examine locomotor behaviour of fishes, including estimating segment-specific movement rates using mark-recapture techniques with a variety of tag types (external tagging such as Peterson disc, passive integrative responders, passive acoustic and radio telemetry), and assessing fine-scale continuous movements and rates using active acoustic telemetry (Holland et al., 1985; Holland et al., 1992; Meyer and Holland, 2001; Bunt et al., 2002), or stationary arrays (Heupel et al., 2006). However, these techniques assume that fish swim in a straight line, and do not account for vertical migrations. Thus current estimates of swim speeds may be conservative.

More advanced techniques can more accurately estimate swim speed by measuring movements associated with propulsion. The major factor determining swim speed is tailbeat frequency (TBF), where tailbeat amplitude varies little at steady swimming and becomes more variable at low swim speeds, bursts and quick turns 
(Webb, 1995). Swim speeds can be estimated using electromyogram (EMG) radio transmitters, which measure swim speed by assessing TBF, rather than inferring swim speed based on time and distance. EMG telemetry sums the electrical impulses of the caudal axial musculature and has been correlated with TBF and swim speed in controlled swim flume experiments and used successfully in a number of field studies (reviewed in Cooke et al., 2004b). However, EMG telemetry requires surgical implantation of electrodes, which increases handling time and stress (Cooke et al., 2004a, 2004b). Some studies suggest that individual EMG tags require calibration with swim speed because slight variations in electrode placement can significantly affect the EMG output and hence its relationship with swim speed (Beddow \& McKinley, 1999; Geist et al., 2002). EMG radio transmitters cannot be used in the marine environment as radio signals become attenuated (See Cooke et al., 2004a) and though acoustic EMG transmitters exist (Dewar et al., 1999; Lembo et al., 2008), they have not been widely adopted and challenges remain with electrodes staying fixed in axial musculature over long migrations.

Development of accelerometer technology has provided new tools for studying the behaviour of marine animals. For example, in fish, acceleration can be used to derive swim speed principally by measuring acceleration associated with tailbeat oscillations (Shepard et al., 2008). Accelerometer data loggers have been developed to record information on movement (three dimensional (Overall Dynamic Body Acceleration (ODBA)) or two dimensional (Partial Dynamic Body Acceleration (PDBA)) acceleration (Shepard et al., 2008) in a wide range of taxa (e.g. humans: Halsey et al., 2008, birds: 
Wilson et al., 2006; Green et al., 2009), including fishes (sharks: Gleiss et al., 2010, salmon: Clark et al., 2010, bonefish: Brownscombe et al., 2013). However, as with all loggers, they have limited applicability for use in many natural environments where it can be difficult to retrieve loggers (Cooke et al., 2004a).

More recently, acoustic transmitters have been developed that measure acceleration in three axes and then transmit an average value to a receiver (Figure 1-1A). The development of an acoustic acceleration transmitter allows for transmission of data, rather than storing data which must be later retrieved and downloaded. Acceleration transmitters report acceleration at a lower sampling frequency (typically $10 \mathrm{~Hz}$ ) than in loggers and calculate root mean square (RMS) acceleration (henceforth referred to as acceleration) to minimize battery drain when transmitting data. The calculated average acceleration is most strongly influenced by the sway axis due to rear propulsion of swimming fish (see Figure 1-1B; Shepard et al., 2008). This new technology has been used to monitor fine scale movement patterns in great barracuda, Sphyraena barracuda (O'Toole et al., 2010) and estimate energy use of bonefish, Albula vulpes (Murchie et al., 2011), and cuttlefish, Sepia apama (Payne et al., 2011). These transmitters can also be fitted with pressure or temperature sensors so information on depth and environmental conditions can be collected.

\section{Pacific Salmon Ecology}

Anadromous Pacific salmon (Oncorhynchus spp.) spawn once and die (semelparity). Of the six species of anadromous and semelparous Pacific salmon, the migration biology of sockeye salmon (Oncorhynchus nerka) is one of the most well 
understood, particularly for sockeye salmon destined for the Fraser River in British Columbia (reviewed in Hinch et al., 2006). Thus, sockeye salmon will be the focus of the following discussion, though many behaviours and trends can be extrapolated to other Pacific salmonids. Like other salmonids, sockeye salmon eggs hatch in freshwater, beginning a life cycle during which they will undergo several migrations. Eggs hatch and larvae remain in the gravel redd until yolk reserves are depleted. Larvae then emerge as alevins and swim to the surface to fill their swim bladder for the first time, before migrating either directly to the ocean or to nursery areas in nearby lakes. Fry spend 1-2 years in nursery lakes prior to smoltification. Smoltification, a complex physiological, morphological and behavioural process characterized by changes in the endocrine system, osmoregulation, and rheotaxis, results in migration from freshwater lakes to the ocean (reviewed in Hinch et al., 2006). Juvenile sockeye salmon migrate in a directed fashion along the coast and out into the open ocean. They spend 2-3 years growing in the ocean before returning to their natal rivers to spawn and die (Hinch et al., 2006).

Comparatively little is known about open ocean and directed coastal migration of adult Pacific salmon, compared with in-river migration, mostly owing to logistical difficulty and technological limitations (see 'Estimating Swim Speed in Fish' section and review by Drenner et al., 2012). The physiological cues responsible for the initiation of the return adult migration are poorly understood but are believed to be related to photoperiod, which triggers maturation through the hypothalamo-pituitary-gonadal (HPG) axis, but only after the stored energy threshold has been exceeded (Ueda et al., 2000). Physiological changes and sexual maturation have been observed as far away as 
$850 \mathrm{~km}$ from the Fraser River and, within $300 \mathrm{~km}$ of the Fraser River, sockeye salmon stop feeding and complete the remaining migration and maturation on endogenous reserves (Hinch et al., 2006). Very little is known about open ocean migration because of logistic challenges associated with studying fish in such vast environments (Hinch et al., 2006).

Once salmon have arrived at the coast, tracking movement is easier and more is known about physiology and behaviour. However, though logistical challenges may be fewer in the narrower and more accessible coastal region, technological limitations have still restricted some measurement of behaviour (such as measuring swim speed from TBF; as mentioned above). Previous work tracking adult coastal migrating sockeye salmon has estimated average swim speeds at $1 \mathrm{BL} \mathrm{s}^{-1}$ (Madison et al., 1972; Stasko et al., 1976; Quinn, 1988; Crossin et al., 2007). Sockeye salmon have been manually tracked at several points along the migratory route including Queen Charlotte Islands, Johnstone Strait, Skeena River Estuary, Strait of Georgia, and Haro Strait and at each of these locations swim speeds were highly variable, both within an individual and across individuals, and ranged between $\sim 0.5-1.5 \mathrm{BL} \mathrm{s}^{-1}$. More recent studies have calculated ground speed on a much coarser scale, by comparing the time between detections at distant arrays and have found that ground speed estimates are also close to $1 \mathrm{BL} \mathrm{s}{ }^{-1}$ (Crossin et al. 2007). Environmental variables such as diel period have been used to explain some variability where individuals swim faster during the day and more slowly at night (Madison et al., 1972). In addition, physiological variables such as sex hormones, cortisol and gill physiology have also been correlated with variability in swim speeds 
(Cooke et al., 2006; Crossin et al., 2007; Crossin et al., 2009; Miller et al., 2009). Much of the swim speed variability within the coastal migration phase has yet to be resolved on a fine temporal scale, and is thus difficult to explain using environmental and physiological variables.

Though not to the same extent as with swim speed, depth use patterns in migrating sockeye salmon have been studied for coastal migration. Diel patterns in depth have been observed where individuals swim deeper during the day and shallower at night (Quinn et al., 1989). Migrating sockeye salmon in Johnstone Strait and the Strait of Georgia swim in the upper $30 \mathrm{~m}$, above the thermocline and near halocline, but have been documented undertaking vertical migrations (actually a form of commuting). These vertical migrations involve quickly ascending to near surface waters, and then returning to deeper waters. They appear to occur more often at night (Quinn et al., 1989), and are believed to aid in navigation, though whether fish are sampling surface waters for olfactory cues, or for other navigational cues, is unknown. Generally, little evidence of 'depth-seeking' behaviours or vertical migrations has been collected for coastally migrating sockeye salmon.

Once at the Fraser River, sockeye salmon can remain in the Fraser River estuary for several days, with some stocks holding in the estuary for up to six weeks. Both osmoregulatory changes (through gill $\mathrm{Na} / \mathrm{K}$ ATPase expression) and sexual maturity (plasma testosterone concentrations) have been correlated with river entry (Cooke et al., 2006; Crossin et al., 2007, 2009). Use of tidal flows to assist in migration into the river has been previously observed (Levy \& Cadenhead, 1995). In the Fraser River mainstem, 
adult sockeye salmon swim on average, between 1.0 - 1.9 $\mathrm{BL} \mathrm{s}^{-1}$ depending on sex, river discharge, and water velocity (Rand \& Hinch, 1998; Hinch \& Rand, 1998; Hinch et al., 2004; Hanson et al., 2008). Males have been observed to swim 1.3 times faster than females (118 $\mathrm{cm} \mathrm{s}^{-1}$ compared to $89 \mathrm{~cm} \mathrm{~s}^{-1}$ for females; Hinch \& Rand, 1998), and fish swim more quickly during years of higher river discharge (Hanson et al., 2008), and in river reaches with higher flows (Hinch \& Rand, 1998).

Local adaptation to historic migration conditions has resulted in over 50 genetically distinct populations of sockeye salmon (Beacham et al., 2004). These populations differ based on river entrance timing, morphology, gross somatic energy reserves, routine and active metabolic rates, and aerobic scope (Crossin et al., 2004, 2009; Eliason et al., 2011). Despite these among population differences, there has been little investigation into how populations differ in terms of migratory swim speeds and behaviour.

\section{Research Objectives}

The general objective of this thesis was to study swim speed and depth use of adult sockeye salmon migration throughout directed coastal migration and entrance into the Fraser River, using acceleration transmitters. The objective of Chapter 2 was to determine whether acoustic acceleration transmitters could be used to measure swim speed and energy use in adult sockeye salmon. This was accomplished through controlled swim trials of tagged fish performed in a Brett-style swim flume across a range of ecologically relevant temperatures. I expected that the acceleration output of the tri-axial accelerometer in the VEMCO transmitters would correlate linearly with TBF, as has been 
seen with previous accelerometers, with higher sampling frequency (Kawabe et al., 2003). I also expected that the tags would not need to be individually calibrated, as all tags were placed in the stomach, and small changes in position would likely lead to very small changes in acceleration. Statistical models were built between accelerometer output and swim speed, as well as accelerometer output and rate of oxygen consumption. I expected the relationship between acceleration output and swim speed to be linear as has been seen in previous studies with fish (Kawabe et al., 2003). I also expected the relationship between $\dot{\mathrm{MO}} 2$ and accelerometer output to be linear as has been observed in Hammerhead sharks (Sphyrna lewini; Gleiss et al., 2010). Finally I expected temperature would positively influence the relationship between $\dot{\mathrm{MO}}_{2}$ and accelerometer output where the slope would increase as temperature increases, since routine and active metabolic rates increase as water temperature is increased (Fry, 1971; reviewed in Brett, 1995). In Chapter 3 of my thesis I tagged sockeye salmon in a coastal area, $250 \mathrm{~km}$ from the Fraser River mouth, and obtained accelerometry information from permanent fixed arrays in northern Strait of Georgia and the entrance of the Fraser River. I used the swim speed model developed in Chapter 2, to estimate swim speed of these fish and examined variability in swim speed and depth in relation to some environmental variables (i.e., location, tide, diel period). I expected swim speed to be higher in freshwater than in seawater due to higher water flows in freshwater. I also expected that diel period, and tide would explain some of the variability in behaviour as previous studies have shown that Pacific salmon swim deeper and slower during the day and faster and more shallow at night, and use tidal currents as an energy saving strategy. I also expected that depth would be influenced by location as salmon may swim near the coastal thermocline, as has 
been shown in previous studies (Quinn et al., 1989), and would swim near the bottom or shore of the Fraser River, taking advantage of the boundary layer and possible flows that would provide forward assists (i.e. reverse eddies; Hinch \& Rand, 2000; Standen et al., 2004). Chapter 4 will integrate the findings of both Chapter 2 and 3 and will present future applications and future directions. 


\section{Figures}

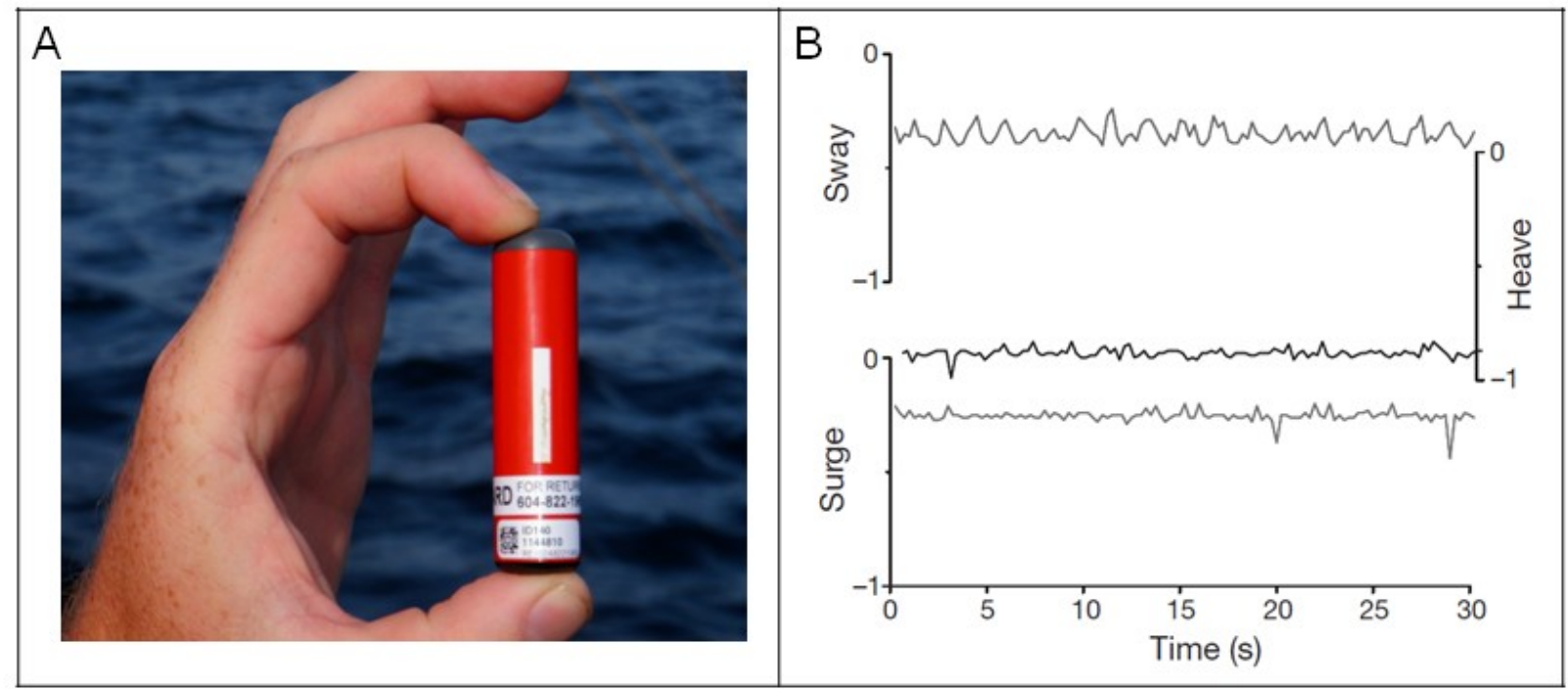

Figure 1-1. Tri-axial acoustic acceleration transmitter A) Photograph of V13AP acceleration transmitter, potted in V16 case B) Dynamic body acceleration (g) of a steady swimming Lemon shark (Negaprion brevirostris), split into three individual axes- sway, heave and surge (adapted from Shepard et al., 2008). 


\title{
Chapter 2: Calibrating acoustic acceleration transmitters for estimating energy use by wild adult Pacific salmon
}

\begin{abstract}
This study is the first to calibrate acceleration transmitters with energy expenditure using a vertebrate model species. I quantified the relationship between acoustic accelerometer output and oxygen consumption across a range of swim speeds and water temperatures for Harrison River adult sockeye salmon (Oncorhynchus nerka). First, I verified that acceleration transmitters with a sampling frequency of $10 \mathrm{~Hz}$ could be used as a proxy for movement in sockeye salmon. Using a mixed effects model, I determined that tailbeat frequency and acceleration were positively correlated ( $p$ $<0.0001)$, independent of tag ID. Acceleration $(\mathrm{p}<0.0001)$ was positively related to swim speed while fork length ( $\mathrm{p}=0.051)$ was negatively related to swim speed. Rate of oxygen consumption and accelerometer output $(\mathrm{p}<0.0001)$ had a positive linear relationship and were temperature dependent $(\mathrm{p}<0.0001)$. There were no differences in swim performance $\left(\mathrm{F}_{2,12}=1.023, \mathrm{p}=0.820\right)$ or oxygen consumption $\left(\mathrm{F}_{1,12}=0.054, \mathrm{p}=0.332\right)$ between tagged and untagged individuals. Five tagged fish were released into the Fraser River estuary and manually tracked. Of the five fish, three were successfully tracked for 1 h. The above relationships were used to determine that the average swim speed was 1.25 \pm 0.03 body lengths $\mathrm{s}^{-1}$ and rate of oxygen consumption was $3.39 \pm 0.17 \mathrm{mg} \mathrm{O}_{2} \mathrm{~kg}^{-1} \mathrm{~min}^{-}$ ${ }^{1}$, averaged across the three detected fish. Acceleration transmitters can be effectively used to remotely evaluate fine-scale behaviour and estimate energy consumption of adult Pacific salmon throughout their homeward spawning migration.
\end{abstract}




\section{Introduction}

Understanding energy use is fundamental to the study of animal physiology, behaviour and evolutionary ecology since the energetic costs of various activities can influence fitness (McNamara \& Houston, 1996). Unfortunately, estimating energy use through measuring metabolic rate $\left(\dot{\mathrm{MO}}_{2}\right)$ in a natural setting has proven difficult, particularly in aquatic organisms. Doubly-labeled water and the heart rate method are the two main methods for the estimation of field metabolic rate in birds and mammals; though both have several well-documented limitations (see review by Butler et al., 2004). However, the doubly-labeled water method has limited applicability in fish because water flux through skin can create errors of up to $50 \%$ (Nagy \& Costa, 1980). Similarly, the heart rate method, which depends on a reliable relationship between heart rate and $\dot{\mathrm{MO}} 2$ suffers in fishes because of the highly variable cardiac stroke volume with physiological state, consequently decreasing the accuracy of the estimate of $\mathrm{MO}_{2}$ (Scharold \& Gruber, 1991; Thorarensen et al., 1996). Thus, alternative methods are required to determine metabolic rate and estimate energy use in a natural setting.

Movement has been successfully used as a proxy for energy use in fish, with tailbeat frequency (TBF) (e.g. Brett, 1965, 1995; Hinch \& Rand, 1998; Lowe et al., 1998) and swim speed (e.g. Brown et al., 2007; Payne et al., 2011) both being well correlated with $\dot{\mathrm{MO}}_{2}$. In nature, integration of TBF and locomotory effort is possible in fish using electromyogram (EMG) telemetry, which sums the electrical impulses of the caudal axial musculature and has been correlated with TBF and swim speed in controlled swim flume experiments. This technique has been used successfully in a number of field studies 
(reviewed in Cooke et al., 2004b), but like heart rate biotelemetry it requires surgical implantation of electrodes, which increases handling time and stress (Cooke et al., 2004a, 2004b). Some studies suggest that individual EMG tags require calibration with swim speed because slight variations in electrode placement can significantly affect the EMG output and hence its relationship with swim speed (Beddow \& McKinley, 1999; Geist et al., 2002). In addition, most EMG studies have involved radio tags, which are limited to use in freshwater environments, and although acoustic EMG tags are available for use in seawater (Lembo et al., 2008), the need to calibrate the tags remains.

Given the above concerns, accelerometer sensors are being posited as an alternative for measuring energy expenditure in fishes. Similar to EMG technology, accelerometer sensors rely on the relationship between swimming activities and energy expenditure (see Halsey et al., 2011). Accelerometer loggers can measure acceleration at high frequencies $(>100 \mathrm{~Hz})$ in up to three axes, providing high-resolution data. Already, they have been successfully used to establish relationships with high correlation coefficients $\left(\mathrm{R}^{2}\right)$ between $\dot{\mathrm{MO}}{ }_{2}$ or $\dot{\mathrm{V}} \mathrm{O}_{2}$ and three dimensional (Overall Dynamic Body Acceleration (ODBA)) or two dimensional (Partial Dynamic Body Acceleration (PDBA)) acceleration (Shepard et al., 2008) in a wide range of taxa (e.g. humans: Halsey et al., 2008; birds: Wilson et al., 2006; Green et al., 2009), including fishes (sharks: Gleiss et al., 2010, salmon: Clark et al., 2010). However, as with all loggers, they have limited applicability for use in a natural environment where it is more difficult to retrieve loggers (Cooke et al., 2004a). Due to many logistical constraints, high costs of working in marine environments, and the need to retrieve tags, studies looking at movement of marine animals have been limited (Drenner et al., 2012). 
The development of an acoustic acceleration transmitter allows for transmission of data, rather than storing data which must be later retrieved and downloaded. Acceleration transmitters report acceleration at a lower sampling frequency (typically 10 $\mathrm{Hz}$ ) than in loggers and calculate root mean square (RMS) acceleration (henceforth referred to as acceleration) to minimize battery drain when transmitting data. This new technology has been used to monitor fine scale movement patterns in great barracuda, Sphyraena barracuda (O'Toole et al., 2010) and estimate energy use of bonefish, Albula vulpes (Murchie et al., 2011) and cuttlefish, Sepia apama (Payne et al., 2011). However, only Payne et al. (2011) used a swim flume to perform controlled calibrations between accelerometer output and $\dot{\mathrm{MO}}_{2}$, finding non-linear correlations between acceleration and both swim speed and $\dot{\mathrm{MO}}_{2}$ for the invertebrate cuttlefish. To date, no studies have calibrated the relationship between $\dot{\mathrm{MO}}_{2}$ and acceleration transmitter output for any vertebrate. Development of species- and life-stage-specific relationships between $\dot{\mathrm{MO}}_{2}$ and acceleration is required before acceleration transmitters can be used to accurately estimate energy expenditure in free-swimming aquatic organisms.

Although sockeye salmon (Oncorhynchus nerka) are the most well studied of the Pacific salmonids in terms of their migratory physiological ecology (Hinch et al., 2006), study of their energy expenditure and overall energy requirements has been limited particularly in the marine environment (Drenner et al., 2012). Indeed, energetic budgets for ocean migration simplistically determine average swim speed by dividing the distance travelled by the time between release and re-capture, an estimate that fails to account for changes in energetic demands due to currents and tides (Quinn et al., 1989). 
Furthermore, energy budgets based on EMG biotelemetry in freshwater have used short river sections and small sample sizes (Hinch \& Rand, 1998; Rand \& Hinch, 1998; Hinch \& Bratty, 2000). Therefore, acoustic acceleration transmitters could find immediate application to follow sockeye salmon migrations in both marine and freshwater environments.

Before research on free swimming sockeye salmon using the acoustic acceleration transmitters can be undertaken, the relationship between movement and body acceleration, as determined by the new acceleration transmitter, must be validated for use in sockeye salmon. Furthermore, a relationship between acceleration and rate of $\dot{\mathrm{MO}}_{2}$ at different temperatures would be required for accurate estimates of energy in the field. Therefore, the objectives of the present study were to determine: (1) if transmitting accelerometers using a $10 \mathrm{~Hz}$ sampling frequency accurately relayed information on swimming activity in adult sockeye salmon (Oncorhynchus nerka); (2) the relationship between accelerometer output and swimming speed, (3) the relationship between accelerometer output and $\dot{\mathrm{MO}}_{2}$ across a range of ecologically relevant temperatures, and (4) a proof-of-principle use of these accelerometers in a natural setting.

\section{Methods}

\section{Fish collection}

This study was conducted in accordance with the guidelines of the Canadian Council of Animal Care, as administered by Carleton University (Animal Care \#B10-06) and the University of British Columbia (Animal Care \#A11-0212). Seventeen Harrison 
River sockeye salmon (O. nerka) were used for this study (10 males and 7 females; fork length $(\mathrm{FL})=57.7-68.9 \mathrm{~cm})$. Harrison River sockeye salmon were captured on September $26^{\text {th }}, 2011$ by beach seine on the Harrison River $\left(49^{\circ} 17^{\prime} \mathrm{N}, 121^{\circ} 54^{\prime} \mathrm{W}\right)$ during their freshwater migration to natal spawning areas. They were transported by truck $(\sim 60$ km) to the Cultus Lake Salmon Research Laboratory (Fisheries and Oceans Canada), where each individual was tagged with a passive integrated transponder. Two scales were removed for population identification via scale analysis (Cook \& Guthrie, 1987), and to ensure fish were of the Harrison River sockeye salmon population. Prior to the swim trials, fish were held in outdoor freshwater circular tanks $(1400 \mathrm{~L})$ for $3-22$ days under seasonal photoperiod at a water speed of $0.30 \mathrm{~m} \mathrm{~s}^{-1}$ and a water temperature of $10.8{ }^{\circ} \mathrm{C}-$ $12.9^{\circ} \mathrm{C}$. Sex was determined by dissection after swim trials were complete. Salmon were not fed, as they naturally cease feeding prior to river entry (at least one week prior to capture).

\section{Swim Trial}

Swim trials were completed on October $1^{\text {st }}-20^{\text {th }}, 2011$ using two Brett-style swim tunnel respirometers (fully described in Jain et al., 1997 and Lee et al., 2003). To encourage steady swimming, the first $100 \mathrm{~cm}$ of the 'upstream' portion of each swim tunnel was covered with black plastic, except for a single strip along the bottom of the tunnel to allow for observation of TBF. Approximately $10-12 \mathrm{~h}$ prior to the first swim trial, each individual was anaesthetized with $\operatorname{MS} 222\left(0.1 \mathrm{~g} \mathrm{~L}^{-1}\right.$ in $\left.0.2 \mathrm{~g} \mathrm{~L}^{-1} \mathrm{NaHCO}_{3}\right)$ before an acceleration transmitter (VEMCO, Halifax, NS. Model V9A-2H, 69 kHz, 16 $\mathrm{mm} \times 67 \mathrm{~mm}$ ) was gastrically inserted (Cooke et al., 2005). This procedure lasted $<2 \mathrm{~min}$ 
and the fish was allowed to recover in the swim tunnel overnight at a water velocity of $0.15 \mathrm{~m} \mathrm{~s}^{-1}$. Each individual completed a standard ramp critical swimming speed $\left(\mathrm{U}_{\text {crit }}\right)$ swim protocol (Jain et al., 1997; Lee et al., 2003) at up to six temperatures $(12,14,16$, 18,20 and $\left.22^{\circ} \mathrm{C}\right)$. Briefly, water velocity was incrementally increased from a resting swim speed of $0.15 \mathrm{~m} \mathrm{~s}^{-1}$ up to $0.65 \mathrm{~m} \mathrm{~s}^{-1}\left(\sim 50 \%\right.$ of $\left.U_{\text {crit }}\right)$ over a 15-min period. Thereafter, the water velocity was increased by $0.15 \mathrm{~m} \mathrm{~s}^{-1}\left(\sim 0.20 \mathrm{BL} \mathrm{s}^{-1}\right)$ every $20 \mathrm{~min}$ until the fish ceased swimming and remained on the rear grid for $>10 \mathrm{~s}$. Once a fish had fatigued, water velocity was decreased to $0.15 \mathrm{~m} \mathrm{~s}^{-1}$ and the individual was allowed to recover for $1 \mathrm{~h}$ following the trial, before temperatures were changed. Temperature was increased or decreased by no more than $4{ }^{\circ} \mathrm{C} \mathrm{h}^{-1}$ (Clark et al., 2008). Once at the required temperature, individuals were allowed $1 \mathrm{~h}$ to equilibrate before the next swim trial began. Two swim trials were completed each day, each at a randomly selected temperature (12, $14,16,18,20$ or $22{ }^{\circ} \mathrm{C}$ ). Once an individual fish was placed in the tunnel, they were allowed to swim at 4 or 6 water temperatures over a period of 2 or 3 days, recovering overnight at the rest swimming speed of $0.15 \mathrm{~m} \mathrm{~s}^{-1}$. In total, 10 individuals (4 females and 6 males) tagged with an accelerometer and 7 control, non-tagged individuals (4 males and 3 females) were tested. One tagged female was excluded from analyses because it refused to swim.

\section{Acceleration and $\mathrm{MO}_{2}$ Data Collection}

Rate of oxygen consumption $\left(\mathrm{M}_{2}\right)$ was measured using a dissolved oxygen probe (Mark IV Oxyguard probe; Point Four Systems, Richmond, BC, Canada), Windaq box (Dataq Instruments, Akron, OH, USA) and Labview software (National Instruments, 
TX, USA), and was calculated from the decrease in dissolved oxygen during the last $\sim 10$ min of each water velocity increment and standardized by body mass (Lee et al., 2003). Dissolved oxygen concentration was maintained above $70 \%$ saturation throughout the entire trial. Blank runs (without fish) were completed before and after experimental trials had been run to check probe drift and microbial $\mathrm{O}_{2}$ uptake, both of which were negligible. A portable acoustic hydrophone was inserted into the top of the swim tunnel and the receiver unit (VR100; VEMCO, Halifax, NS, Canada) recorded acceleration data throughout each swim trial. Accelerometers measured acceleration in three axes, for $10 \mathrm{~s}$ with a sampling frequency of $10 \mathrm{~Hz}$. The root mean square (RMS) acceleration was calculated by averaging acceleration in all three dimensions using equation; RMS = $\left(\mathrm{X}^{2}+\mathrm{Y}^{2}+\mathrm{Z}^{2}\right)^{0.5}$, transmitted every $13-17 \mathrm{~s}$ and had a range of $0-4.901 \mathrm{~m} \mathrm{~s}^{-2}$. Swim trials were recorded using one wide-angle, black and white video camera (Panasonic WVBP312; $4.5 \mathrm{~mm}$ focal length) in aluminum casing, connected to a time-lapse VCR (Panasonic AG-6124, Panasonic, Secaucus, NJ, USA) to allow for later quantification of TBF. $U_{\text {crit }}$ was calculated according to Beamish (1978).

Tailbeat frequency was determined during the first 5 min of each $\dot{M O}_{2}$ measurement from the $14{ }^{\circ} \mathrm{C}$ swim trial by counting tailbeats during the 10 -s period that corresponded with the 10 -s sampling period for the accelerometer $(\sim 1510$-s period per speed increment). Swim speed was corrected for blocking effect (Jones et al., 1974), and compared to mean acceleration during the last 10 min of each swim speed increment. $\dot{\mathrm{MO}} 2$ was compared with the mean acceleration during the $\dot{\mathrm{MO}}{ }_{2}$ sampling period. 


\section{Field Assessment of Acceleration Transmitter Performance}

Sockeye salmon for field assessments were caught by rod and reel angling using a charter vessel in the Fraser River estuary throughout September, 2011 ( $\mathrm{n}=5$; water temperature $\left.=10-13{ }^{\circ} \mathrm{C}\right)$. Fish were placed in a foam-lined trough filled with water, and an acceleration transmitter (VEMCO, Halifax, NS. Model V9AP-2H, $69 \mathrm{kHz}, 16 \mathrm{~mm} x$ $67 \mathrm{~mm}$ ) equipped with a pressure sensor was inserted into the stomach via gastric insertion, as in the laboratory experiment. Unlike the laboratory experiment, an anesthetic was not used in an effort to decrease handling time and minimize behavioural changes. The accelerometer sampling time period was the same as the V9A tags used in the laboratory experiment (mean acceleration in three axes over $10 \mathrm{~s}$, at rate of $10 \mathrm{~Hz}$ ). The V9AP tags transmitted every $13-17 \mathrm{~s}$, alternating between acceleration and depth (m). A blood sample was taken via caudal venipuncture using a vacutainer tube (4 ml, sodiumheparin anticoagulant, $\mathrm{BD}, \mathrm{NJ} ; 21 \mathrm{G}, 11 / 2$ ' long syringe; $\mathrm{BD}, \mathrm{NJ})$, placed on ice water slurry for $<30 \mathrm{~min}$, and centrifuged for $5 \mathrm{~min}$ at $1500 \mathrm{rpm}$ (Clay Adams Compact II Centrifuge, Becton-Dickson; Sparks, MD). Erythrocytes and plasma were separated and flash frozen in liquid nitrogen and stored at $-80{ }^{\circ} \mathrm{C}$ until analysis. Sex was later determined by comparing plasma testosterone and $17 \beta$-estradiol which were determined using radioimmunoassay (McMaster et al., 1992). Fork length of fish was measured, and a tissue $(<0.1 \mathrm{~g})$ sample from the adipose fin was collected for population identification (Beacham et al., 1995, 2004). Fish were immediately released, and manually tracked for up to $1 \mathrm{~h}$ using VR100 portable acoustic hydrophone and receiver unit. Cost of transport (COT) was calculated according to Lee et al. (2003) where COT is a measure of the amount of energy used in relation to the distance travelled. 


\section{Statistics}

Statistical analyses were completed using RStudio (v. 0.94.110) with 'nlme' (Pinheiro et al., 2013), and 'AICcmodavg' (Mazerolle, 2012) packages. Data were tested for normality and homoscedasticity. Data failing homoscedasticity were square root transformed. Linear mixed model was used to describe the relationship between TBF and acceleration, as well as the relationship between swim speed and acceleration, and $\dot{\mathrm{MO}} 2$ and acceleration, using temperature, sex, and FL as covariables where applicable and with subject ID as a random factor (to account for non-independence of data). The most parsimonious models were chosen based on second-order information criterion (AICc) (Sugiura, 1978). Mixed model regressions were run with a group of fish implanted with the same acceleration transmitter. Two regressions were completed using six fish implanted with unique tag ID's, a full model, incorporating random slope and random intercept, was compared to a reduced model, which held only intercept as random using AICc. Comparisons between tagged and non-tagged individuals were made using student t-test, with treatment (tagged/non-tagged) as categorical predictor variable. Significance levels for all tests were $\mathrm{p}<0.05$.

\section{Results}

Sockeye salmon maintained steady-state swimming at water velocities between $1 \mathrm{BL} \mathrm{s}^{-1}$ and $1.75 \mathrm{BL} \mathrm{s}^{-1}$. Below $1 \mathrm{BL} \mathrm{s}^{-1}$ tailbeats were irregular while at swim speeds exceeding 1.75 $\mathrm{BL} \mathrm{s}^{-1}$ fish exhibited "burst and coast" behaviour whereby fish would burst to the front of the tunnel and fall back to the back of the swim tunnel. Maximum $\dot{\mathrm{MO}} 2$ of tagged individuals at $14{ }^{\circ} \mathrm{C}\left(9.92 \pm 0.42 \mathrm{mg} \mathrm{O} \mathrm{kg}^{-1} \mathrm{~min}^{-1}\right)$ was not significantly 
different $(\mathrm{t}=0.675$, d.f. $=13, \mathrm{p}=0.523)$ compared with non-tagged individuals $(9.50 \pm$ $\left.0.52 \mathrm{mg} \mathrm{O}_{2} \mathrm{~kg}^{-1} \mathrm{~min}^{-1}\right)$. The same was true for $\mathrm{U}_{\text {crit }}$ at $14{ }^{\circ} \mathrm{C}$ (tagged $=1.75 \pm 0.07 \mathrm{BL} \mathrm{s}^{-1}$, $1.32 \pm 0.07 \mathrm{~m} \mathrm{~s}^{-1}$ and non-tagged $=1.66 \pm 0.09 \mathrm{BL} \mathrm{s}^{-1}, 1.22 \pm 0.09 \mathrm{~m} \mathrm{~s}^{-1} ; \mathrm{t}=0.783$, d.f. $=$ 13, $\mathrm{p}=0.448) . \dot{\mathrm{O}}_{2}$ did not differ significantly between tagged males $(10.27 \pm 0.43 \mathrm{mg}$ $\left.\mathrm{O}_{2} \mathrm{~kg}^{-1} \mathrm{~min}^{-1}\right)$ and tagged females $\left(9.23 \pm 0.61 \mathrm{mg} \mathrm{O}_{2} \mathrm{~kg}^{-1} \mathrm{~min}^{-1}\right)(\mathrm{t}=-1.371$, d.f. $=7, \mathrm{p}=$ 0.213 ). The same was true for $\mathrm{U}_{\text {crit }}$ (males $=1.71 \pm 0.10 \mathrm{BL} \mathrm{s}^{-1}, 1.37 \pm 0.07 \mathrm{~m} \mathrm{~s}^{-1}$ and females $=1.81 \pm 0.15 \mathrm{BL} \mathrm{s}^{-1}, 1.24 \pm 0.10 \mathrm{~m} \mathrm{~s}^{-1} ; \mathrm{t}=0.583$, d.f. $\left.=7, \mathrm{p}=0.578\right)$.

\section{Tailbeat Frequency, Swim Speed and $\dot{M}_{2}$}

The relationship between acceleration and TBF for each of the nine fish was determined at $14^{\circ} \mathrm{C}$ (Figure 2-1, left column). There was a significant positive linear relationship between acceleration and TBF for all individuals, with an overall $\mathrm{R}^{2}$ of 0.81 (range 0.55 to 0.87 ; Table 2-1). Of the nine fish tested, six fish were implanted with unique tag IDs (see Figure 2-2B). Two regressions were completed using these six fish, the full model, incorporating random slope and random intercept was compared to the reduced model, incorporating only slope. The reduced model was a better fit $(\triangle \mathrm{AICc}=0)$ than the full model $(\triangle \mathrm{AICc}=2.08)$. Three fish were implanted with the same tag (see Figure 2-2A). The relationship between acceleration and TBF for all nine fish was determined using the reduced mixed model, where the model with the best fit included sex and TBF as predictor variables and fish ID was held as a random variable. There was a significant interaction between TBF and $\operatorname{sex}(\mathrm{p}=0.002$; Table 2-2), whereby TBF was lower for males. 
Acceleration values varied with swimming speed (Figure 2-1, center column; Figure 2-4). The model of swim speed and acceleration was determined using a mixed model, with FL and acceleration as predictor variables and fish ID held as the random variable. Acceleration $(\mathrm{p}<0.0001)$ had positive effects on swim speed whereas fork length $(\mathrm{p}=0.051)$ had a negative effect on swim speed (Table 2-2).

$\dot{\mathrm{MO}}{ }_{2}$ of each fish increased with increasing acceleration values (Figure 2-1; right column, Figure 2-3). The relationship between $\mathrm{MO}_{2}\left(\mathrm{mg} \mathrm{O}_{2} \mathrm{~kg}^{-1} \mathrm{~min}^{-1}\right)$ and acceleration $\left(\mathrm{m} \mathrm{s}^{-2}\right)$ was developed using mixed model, where FL, temperature, sex, and acceleration were predictor variables and fish ID was held as a random factor. Acceleration $(\mathrm{p}<0.0001)$ and temperature $(\mathrm{p}<0.0001)$ were the only significant predictor variables, both having positive effects on $\dot{\mathrm{O}}_{2}$. FL and sex were non-significant ( $\mathrm{p}>0.05$; Table 22; Figure 2-3).

Equ. 1: $\dot{\mathrm{MO}}{ }_{2}=0.22\left(\right.$ Temperature $\left.\left({ }^{\circ} \mathrm{C}\right)\right)+\left(\begin{array}{cc}0.61 & \text { Male } \\ 0 & \text { Female }\end{array}\right)-0.05(\mathrm{FL})+$ 4.39(Acceleration) -0.12

\section{Field Assessment}

Of the five fish tagged (three males, two females) with acceleration transmitters, three fish (one male, two females; all Harrison River population) were tracked for up to 1 $\mathrm{h}$ after release, but two fish (two males; one Harrison River and one Weaver Creek population) immediately travelled outside of the detection radius of the manually tracking area so no acceleration values were recorded. Acceleration values from three tracked fish ranged from 0.538 to $2.845 \mathrm{~m} \mathrm{~s}^{-2}$, which are within the range of acceleration values observed in controlled swim trials (see Figure 2-5). Mean ( $\pm \mathrm{SE}$ ) swimming speed was 
estimated as $1.25 \pm 0.03 \mathrm{BL} \mathrm{s}^{-1}$ and mean $\mathrm{MO}_{2}$ as $3.39 \pm 0.17 \mathrm{mg} \mathrm{O}_{2} \mathrm{~kg}^{-1} \mathrm{~min}^{-1}$ using the swim speed-acceleration and acceleration- $\mathrm{MO}_{2}$ models (Equ.1) for $11.0{ }^{\circ} \mathrm{C}$. Mean COT of adult sockeye salmon swimming in the Fraser River estuary was $0.070 \pm 0.002 \mathrm{mg} \mathrm{O} 2$ $\mathrm{kg}^{-1} \mathrm{~m}^{-1}$

\section{Discussion}

Despite being the most well studied of the Pacific salmon (reviewed in Hinch et al., 2006), little is known about energy use of returning adult sockeye salmon throughout their marine migration. The few studies that directly examined energy use using activity transmitters (EMG) were limited to freshwater assessments in short segments of sockeye salmon's river migration, and had relatively small sample sizes (Hinch \& Rand, 1998; Rand \& Hinch, 1998). The development of acoustic acceleration transmitters has enabled the remote observation of fine-scale activity and energy use patterns in both the marine and freshwater sections of spawning migration. However, use of such tags for field-based studies of energetics is predicated on the calibration of transmitter output with $\dot{\mathrm{MO}}_{2}$ and swimming speed. This study was the first validation of acoustic acceleration transmitters to estimate energy expenditure in a free-swimming vertebrate, thus supporting the use of this technique for monitoring tagged animals released into the wild.

Accelerometer loggers operating at a higher sampling frequency and for continuous periods compared with transmitters have been shown to accurately reflect swimming movement patterns in fish (Shepard et al., 2008; Gleiss et al., 2010). Nevertheless, the strong linear correlations between TBF and acceleration for each individual in the current study $\left(0.55>\mathrm{R}^{2}<0.87\right.$; mean $\left.=0.81\right)$ at acceleration values $<3$ 
$\mathrm{m} \mathrm{s}^{-2}$, clearly shows that a much lower sampling frequency $(10 \mathrm{~Hz})$ and sampling period (10 s) are adequate for estimation of $\dot{\mathrm{MO}}_{2}$ in adult migrating sockeye salmon. Previously, accelerometer loggers used in aquatic organisms provided a correlation coefficient between acceleration and movement of around 0.7 , as found in the present study, which is lower than the 0.9 correlation coefficient typical of terrestrial organisms (Gleiss et al., 2010; Halsey et al., 2009). Above a TBF of $2.5 \mathrm{~Hz}$, fish began to exhibit bursting behaviour, resulting in higher acceleration values and weakening the correlation between TBF and acceleration. Accelerations beyond $3.0 \mathrm{~m} \mathrm{~s}^{-2}$ failed to follow any relationship and were excluded from this study. Acceleration varied only slightly at a given swim speed $\left(\mathrm{R}^{2}=0.78\right)$, indicating that the accelerometer output successfully integrated aspects of locomotion beyond TBF that contribute to swimming speed, such as tailbeat amplitude and other fine-scale differences in locomotion. It is unclear from the present experiments why high accelerations were not correlated with swimming speed. Future studies could examine both TBF and tailbeat amplitude to resolve this problem. Nevertheless, TBF and acceleration provided a strong correlation that proved useful for examining fish swimming in a natural setting.

Sockeye salmon used here had naturally ceased feeding as part of their spawning migration and could be tagged via gastric insertion. Thus, handling time under anesthesia was greatly reduced compared with EMG and electrocardiogram (ECG) tagging, which require surgical implantation. Whereas positioning and securing of EMG and ECG tags are under precise control, exact orientation and position cannot be controlled during gastric insertion. To determine if potential tag placement differences altered the individual relationships between TBF and acceleration, a full mixed model was compared 
with a reduced mixed model (Brown et al., 2007). The reduced model was a better fit, suggesting that the calibration relationships were not dependent on exact tag placement and could be applied to other non-calibrated sockeye salmon in nature. The regressions for six fish tagged with unique tag IDs did not differ, and likewise the regressions for three individuals tagged with the same tag ID were not different. Data from each fish were grouped to determine a single relationship between TBF and acceleration. This demonstrated that the acceleration transmitters, sampling at a rate of $10 \mathrm{~Hz}$ for $10 \mathrm{~s}$, accurately reflected swimming activity of adult sockeye salmon, independent of precise gastric placement and orientation.

Ambient water temperature is the driving factor of basal metabolic rate in fish (Fry, 1971; Brett, 1995). Previous studies have shown that individual adult sockeye salmon experience water temperatures ranging between 8 and $21{ }^{\circ} \mathrm{C}$ during their upriver spawning migration (Patterson et al., 2007). As a result they have population specific differences in thermal tolerance, and aerobic scope (Eliason et al., 2011). In this study we examined both routine and active metabolic rate in fish over a thermal range $\left(12-22{ }^{\circ} \mathrm{C}\right)$, which incorporates both typical temperatures experienced by migrating sockeye salmon, as well as an extreme temperature $\left(22{ }^{\circ} \mathrm{C}\right)$ that is rarely experienced by migrating adult sockeye salmon, and considered to be at the limit of thermal tolerance (Eliason et al., 2011). Sockeye salmon can experience highly variable water temperatures within a short period of time (Patterson et al., 2007) and can rapidly acclimate to a change of $4{ }^{\circ} \mathrm{C} \mathrm{h}^{-1}$ used in this experiment (Clark et al., 2008). Although adult Harrison River sockeye salmon have a very shallow and broad aerobic scope (Eliason et al., 2013), temperature 
was found to be a significant predictor of oxygen consumption (Equ. 1), and was included in the model.

Movement is correlated to energy use in migrating sockeye salmon (Brett, 1965). Correspondingly, the acceleration transmitters relayed information that provided a strong relationship between acceleration and $\mathrm{MO}_{2}$. Linear regressions of all fish grouped together for each temperature indicated a strong correlation between $\dot{\mathrm{MO}}_{2}$ and acceleration. The model of best fit revealed that $\mathrm{MO}_{2}$ was positively related to both acceleration and temperature. These findings are consistent with previous work showing that $\dot{\mathrm{MO}}_{2}$ in sockeye salmon varies with swim speed and temperature (Brett, 1965; Eliason et al., 2011). Moreover, the model of $\dot{\mathrm{MO}}_{2}$ and acceleration can be used to generate empirically validated estimates of energy use by migrating adult sockeye salmon using acoustic accelerometers.

The final objective of this study was to conduct a field-based proof-of-principle validation of the acoustic acceleration transmitters. Manual tracking revealed accelerations well within the calibrated range for both $\mathrm{TBF}$ and $\mathrm{MO}_{2}$, obviating any problem associated with high accelerations. It is possible that tagged and released sockeye salmon were physiologically exhausted and thus exhibited decreased activity compared to unhandled fish. Future studies should interpret acceleration values that fall outside of the calibrated range cautiously. The relatively low power output of V9 tags made manual tracking a challenge since two fish quickly escaped the receiver detection radius. Acceleration transmitters with a higher power output (i.e. VEMCO V13 tags with 
higher $\mathrm{dB}$ ) are now available, which increases detection radius and may facilitate both manual tracking efforts and increase detection efficiency of stationary acoustic receivers.

Although this study demonstrated that acceleration transmitters can relay information on swimming speed and estimate energy use in nature, the ecological relevance of these values must be evaluated. The estimate of average swim speed $(\sim 1.3$ $\left.\mathrm{BL} \mathrm{s} \mathrm{s}^{-1}\right)$ is very similar to optimal speed $\left(\sim 1 \mathrm{BL} \mathrm{s}^{-1}\right)$ reported elsewhere for marine migrating adult Pacific salmon (reviewed in Drenner et al., 2012), and so appears realistic. Using respirometry, Wagner et al. (2006) found that sockeye salmon swimming at speeds close to $1.25 \mathrm{BL} \mathrm{s}^{-1}$ consumed $\sim 11.0 \mathrm{mg} \mathrm{O}_{2} \mathrm{~kg}^{-1} \mathrm{~min}^{-1}$ at $12.5{ }^{\circ} \mathrm{C}$ in freshwater, whereas Brett (1965) found that $\mathrm{MO}_{2}$ was $2.93 \mathrm{mg} \mathrm{O}_{2} \mathrm{~kg}^{-1} \mathrm{~min}^{-1}$ at $15^{\circ} \mathrm{C}$. In this study, $\dot{\mathrm{MO}} 2$ for three tracked fish was estimated as $\sim 3.4 \mathrm{mg} \mathrm{O}_{2} \mathrm{~kg}^{-1} \mathrm{~min}^{-1}$ using laboratory derived calibrations. However, Wagner et al. (2006) found a 27\% higher $\dot{\mathrm{MO}}_{2}$ for sockeye salmon swimming at $\sim 1.25 \mathrm{BL} \mathrm{s}^{-1}$ in seawater compared with freshwater. Since the laboratory calibrations were performed in freshwater, and study fish were swimming in seawater, a correction for $27 \%$ should be applied, which yields an average $\dot{\mathrm{MO}} 2$ of 4.3 $\mathrm{mg} \mathrm{O} \mathrm{Og}^{-1} \mathrm{~min}^{-1}$, and is still well within the range of observed rates of $\dot{\mathrm{MO}} 2$ in seawater ( $\sim 4.0$ to $15.0 \mathrm{mg} \mathrm{O} \mathrm{kg}^{-1} \mathrm{~min}^{-1}$, at $12.5{ }^{\circ} \mathrm{C}$; Wagner et al., 2006). Nevertheless, the energetic cost of swimming in seawater needs to be confirmed in seawater laboratory studies over a range of temperatures to ensure accuracy of field-based estimates of metabolic rates.

To date, few studies have directly measured adult sockeye salmon $\dot{\mathrm{MO}}_{2}$ to estimate COT under laboratory conditions (e.g., Brett, 1965; Lee et al., 2003; MacNutt et 
al., 2006). For example, Lee et al. (2003) found COT varied from $\sim 0.14 \mathrm{mg} \mathrm{O}_{2} \mathrm{~kg}^{-1} \mathrm{~m}^{-1}$ to $0.21 \mathrm{mg} \mathrm{O}_{2} \mathrm{~kg}^{-1} \mathrm{~m}^{-1}$ at $1.25 \mathrm{BL} \mathrm{s}^{-1}$ at $12{ }^{\circ} \mathrm{C}$. Wagner et al. (2006) found that COT was $\sim 0.12 \mathrm{mg} \mathrm{O}_{2} \mathrm{~kg}^{-1} \mathrm{~m}^{-1}$ in freshwater and $\sim 0.17 \mathrm{mg} \mathrm{O}_{2} \mathrm{~kg}^{-1} \mathrm{~m}^{-1}$ in seawater. Only one study has estimated COT in the field, which was $0.14 \mathrm{mg} \mathrm{O}_{2} \mathrm{~kg}^{-1} \mathrm{~m}^{-1}$ at $18^{\circ} \mathrm{C}$ for freeswimming adult sockeye salmon in a non-constricted reach of the Fraser River (Hinch \& Rand, 1998). Using laboratory derived calibrations, we estimated COT to be $\sim 0.07 \mathrm{mg} \mathrm{O}_{2}$ $\mathrm{kg}^{-1} \mathrm{~m}^{-1}$ for fish swimming in freshwater and $\sim 0.09 \mathrm{mg} \mathrm{O}_{2} \mathrm{~kg}^{-1} \mathrm{~m}^{-1}$ for fish swimming in saltwater in the Fraser River estuary. Temperature differences among studies could contribute to some but not all of slight differences in COT among studies, since Lee et al. (2003) showed a clear positive relationship between COT and temperature. Overall, it was determined that both rate of $\dot{\mathrm{MO}}_{2}$ and COT estimated using acceleration transmitters, were ecologically realistic as they fell close to previously observed values.

In conclusion, this study verified that the acceleration information from VEMCO V9A transmitters can be used as a proxy for swimming speed in laboratory trials, and that laboratory-derived calibrations can be used to estimate COT in freeswimming fish in a natural environment. The above estimates of average swimming speed and COT in nature were well within previously observed range derived in laboratory studies. Thus, VEMCO acceleration transmitters are a promising new tool for advancing the understanding of the activity patterns and energetics of fish in the wild. 


\section{Tables}

Table 2-1. Linear regressions for TBF and acceleration at $14{ }^{\circ} \mathrm{C}$ for each of the nine fish tagged with acceleration transmitters.

\begin{tabular}{ccccccc}
\hline Fish ID & Sex & FL $(\mathrm{cm})$ & Tag ID & $\mathrm{m}$ & $\mathrm{b}$ & $\mathrm{R}^{2}$ \\
\hline 1759 & $\mathrm{~F}$ & 60.5 & 22 & 0.95 & -1.16 & 0.64 \\
3645 & $\mathrm{M}$ & 63.5 & 25 & 1.13 & 1.24 & 0.75 \\
6849 & $\mathrm{M}$ & 67.2 & 21 & 1.26 & -1.68 & 0.87 \\
$1 \mathrm{E} 09$ & $\mathrm{M}$ & 64.3 & 23 & 0.83 & -0.67 & 0.55 \\
3F07 & $\mathrm{M}$ & 63.4 & 21 & 1.08 & -1.35 & 0.82 \\
4F25 & $\mathrm{F}$ & 61.2 & 24 & 1.04 & -1.00 & 0.86 \\
557E & $\mathrm{M}$ & 60.0 & 26 & 1.34 & -1.94 & 0.85 \\
$6 \mathrm{~B} 2 \mathrm{C}$ & $\mathrm{M}$ & 68.9 & 26 & 1.61 & -2.33 & 0.72 \\
7F2F & $\mathrm{F}$ & 64.5 & 23 & 0.96 & -0.95 & 0.74 \\
\hline
\end{tabular}

$\mathrm{m}=$ slope, $\mathrm{b}=\mathrm{y}$-intercept of the linear regression between TBF and acceleration 
Table 2-2. Significance of variables and variable interactions for acceleration and TBF, acceleration and swim speed and $\dot{\mathrm{MO}} 2$ and acceleration relationships for the nine fish tagged for the laboratory study.

\begin{tabular}{lcc}
\hline Acceleration \& Tailbeat Frequency & $\begin{array}{c}\text { Parameter } \\
\text { Estimate }\end{array}$ & p value \\
\hline Intercept & -1.0613 & $<0.0001$ \\
Sex & -0.3881 & 0.0769 \\
TBF & 0.9963 & $<0.0001$ \\
TBF*Sex & 0.1735 & 0.0020 \\
\hline Swim speed \& Acceleration & Parameter & p value \\
\hline Intercept & Estimate & 0.0114 \\
FL & 2.5560 & 0.0508 \\
Acceleration & -0.0358 & $<0.0001$ \\
\hline MO ${ }_{2}$ \& Acceleration & 0.6250 & p value \\
\hline Intercept & Parameter & 0.0200 \\
Acceleration & Estimate & $<0.0001$ \\
FL & 1.3708 & 0.1567 \\
Sex & 0.8772 & 0.0627 \\
Temperature & -0.0151 & $<0.0001$ \\
\hline
\end{tabular}




\section{Figures}
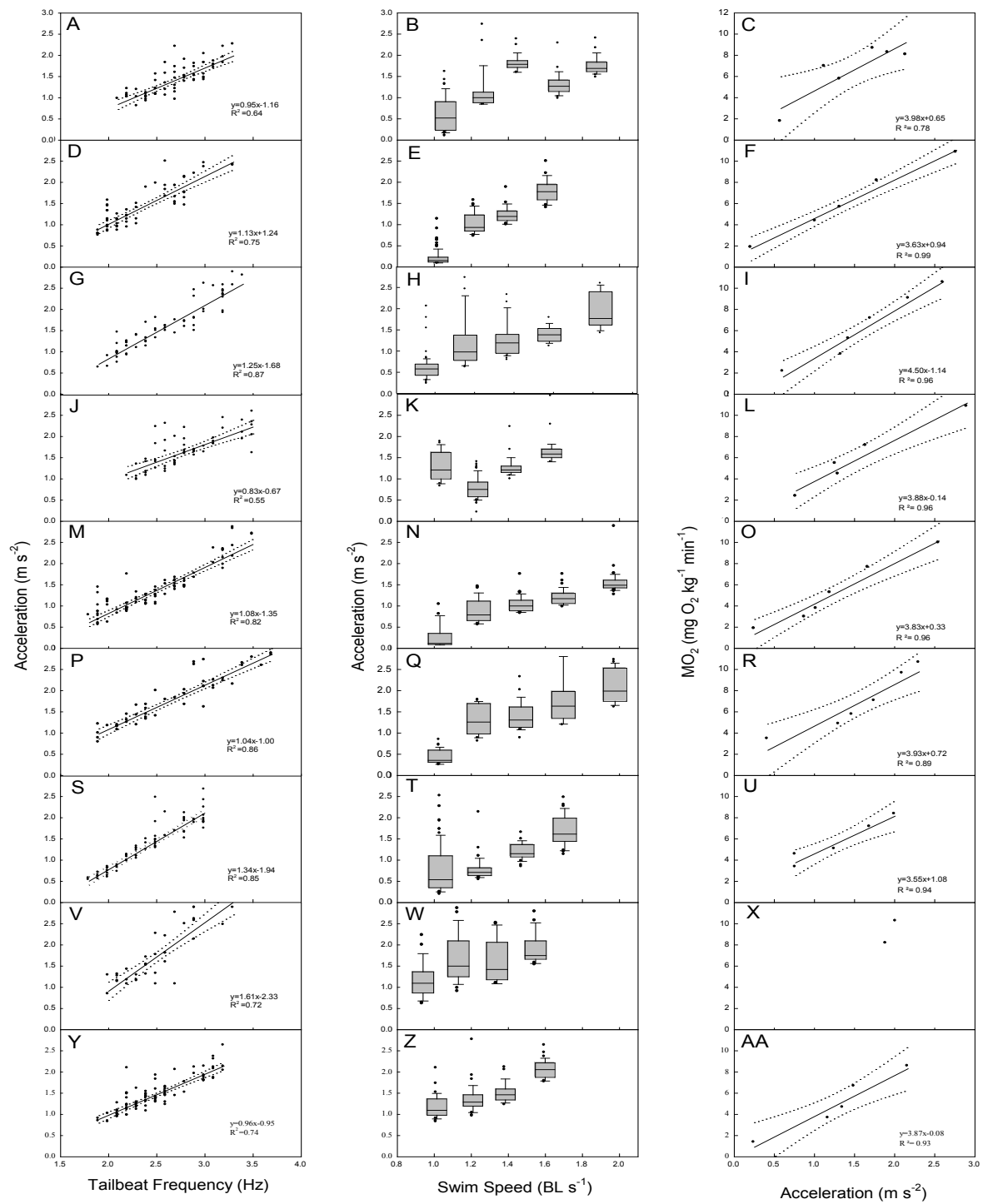

Figure 2-2. Relationships between acceleration and TBF (left column), acceleration and swim speed (center column), and $\dot{\mathrm{MO}}_{2}$ and acceleration ( $=\mathrm{m} \mathrm{s}^{2}$; right column) for individual sockeye salmon at $14^{\circ} \mathrm{C}$. Each row represents relationships for a single fish. Dotted lines represent 95\% confidence intervals. 


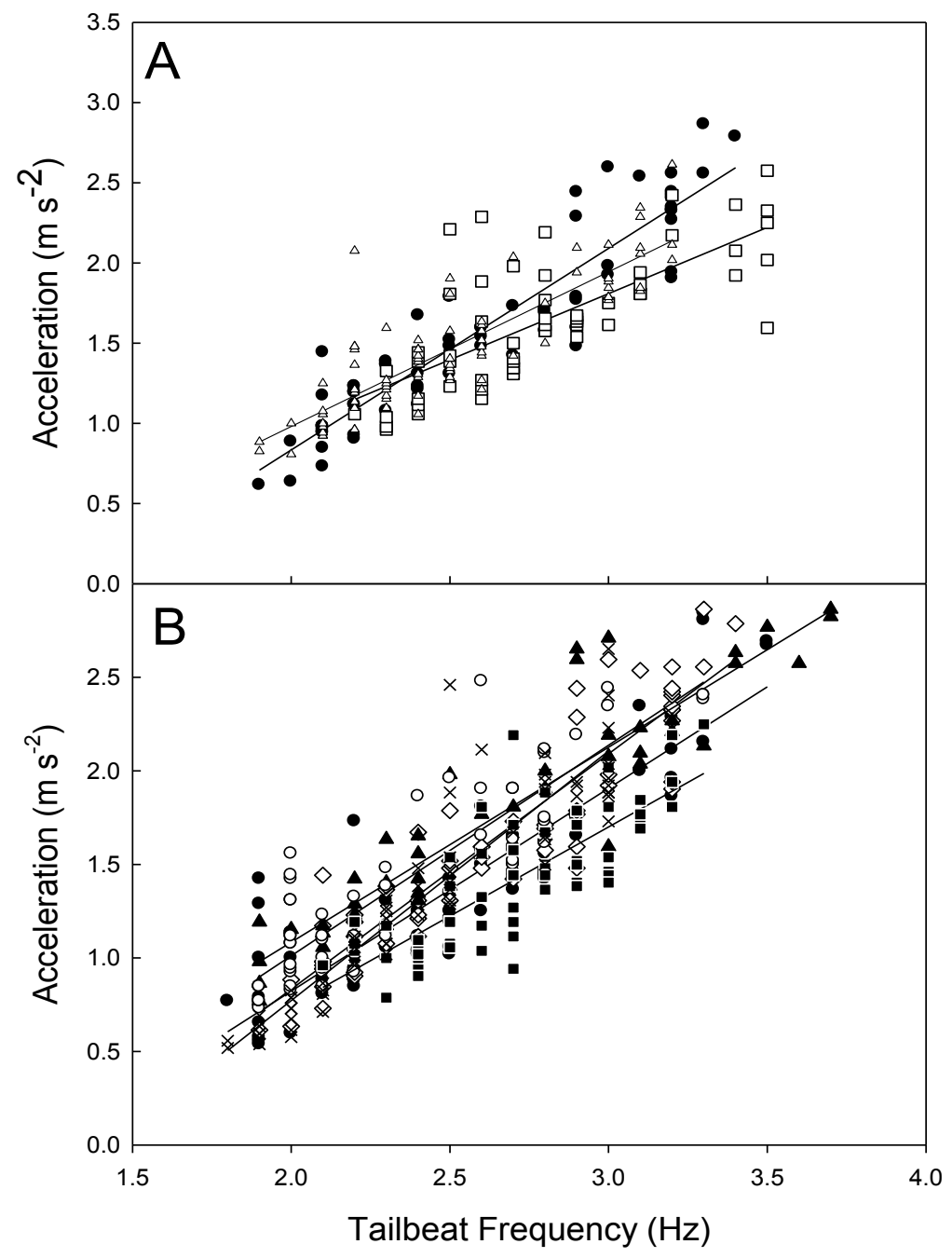

Figure 2-3. The relationship between $\mathrm{TBF}$ and acceleration at $14^{\circ} \mathrm{C}$ for $\mathrm{A}$ ) three adult sockeye tagged with the same V9A-2H acceleration transmitter and B) six individual adult sockeye salmon gastric tagged with six unique V9A-2H acceleration transmitters. Each line represents the relationship between TBF and acceleration for a single fish. Each symbol represents an individual sockeye salmon. (Open symbols = females; closed symbols $=$ males $)$. 


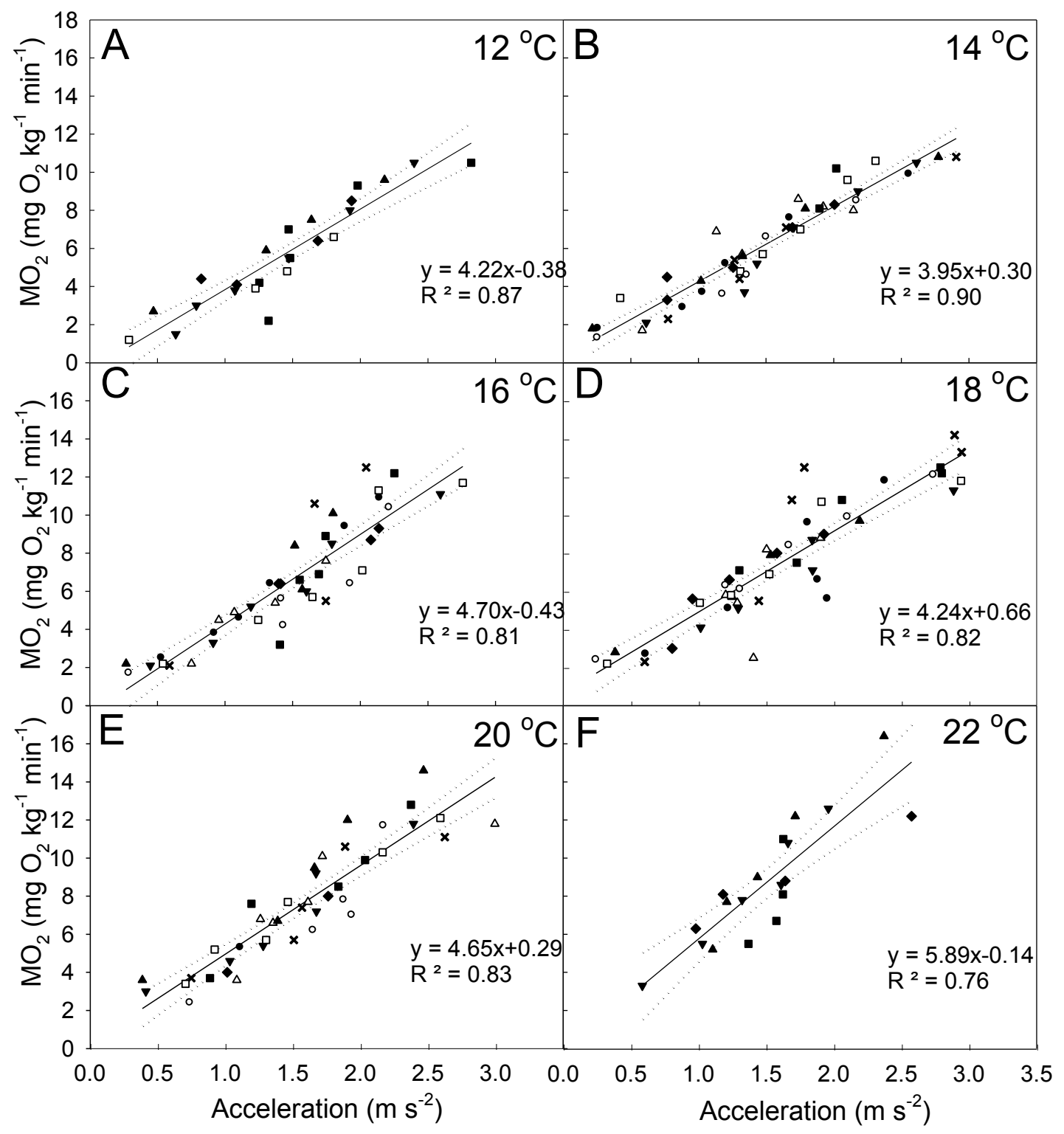

Figure 2-4. Relationship between $\mathrm{MO}_{2}$ and acceleration at A) $\left.\left.12^{\circ} \mathrm{C}, \mathrm{B}\right) 14^{\circ} \mathrm{C}, \mathrm{C}\right) 16^{\circ} \mathrm{C}$, D) $18^{\circ} \mathrm{C}$, E) $20^{\circ} \mathrm{C}$ and F) $22^{\circ} \mathrm{C}$. Each line represents the relationship between $\dot{\mathrm{MO}}_{2}$ and acceleration for all fish swam at a given temperature. Each symbol represents and individual sockeye salmon. $($ Open symbols $=$ females; closed symbols $=$ males $)$. 


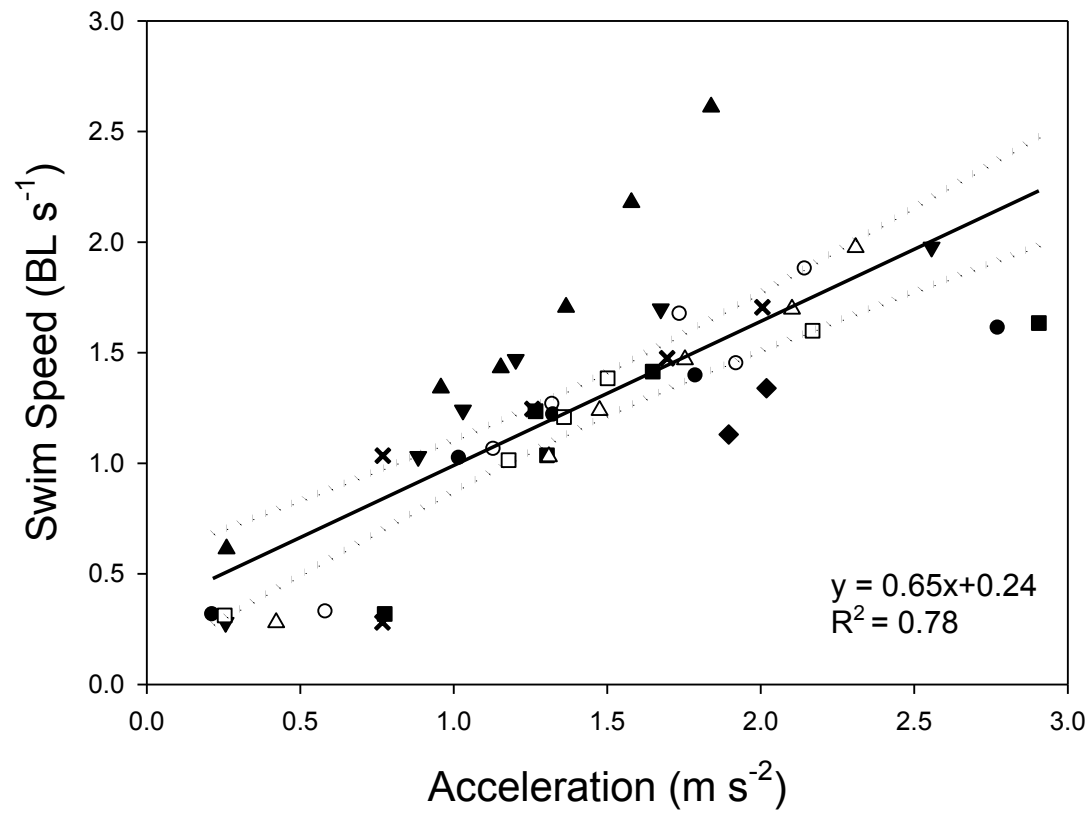

Figure 2-5. Relationship between acceleration and swim speed at $14{ }^{\circ} \mathrm{C}$. Each line represents the relationship between acceleration and swim speed for all fish. Each symbol represents and individual sockeye salmon. (Open symbols $=$ females; closed symbols $=$ males). Dotted lines represent 95\% confidence intervals. 


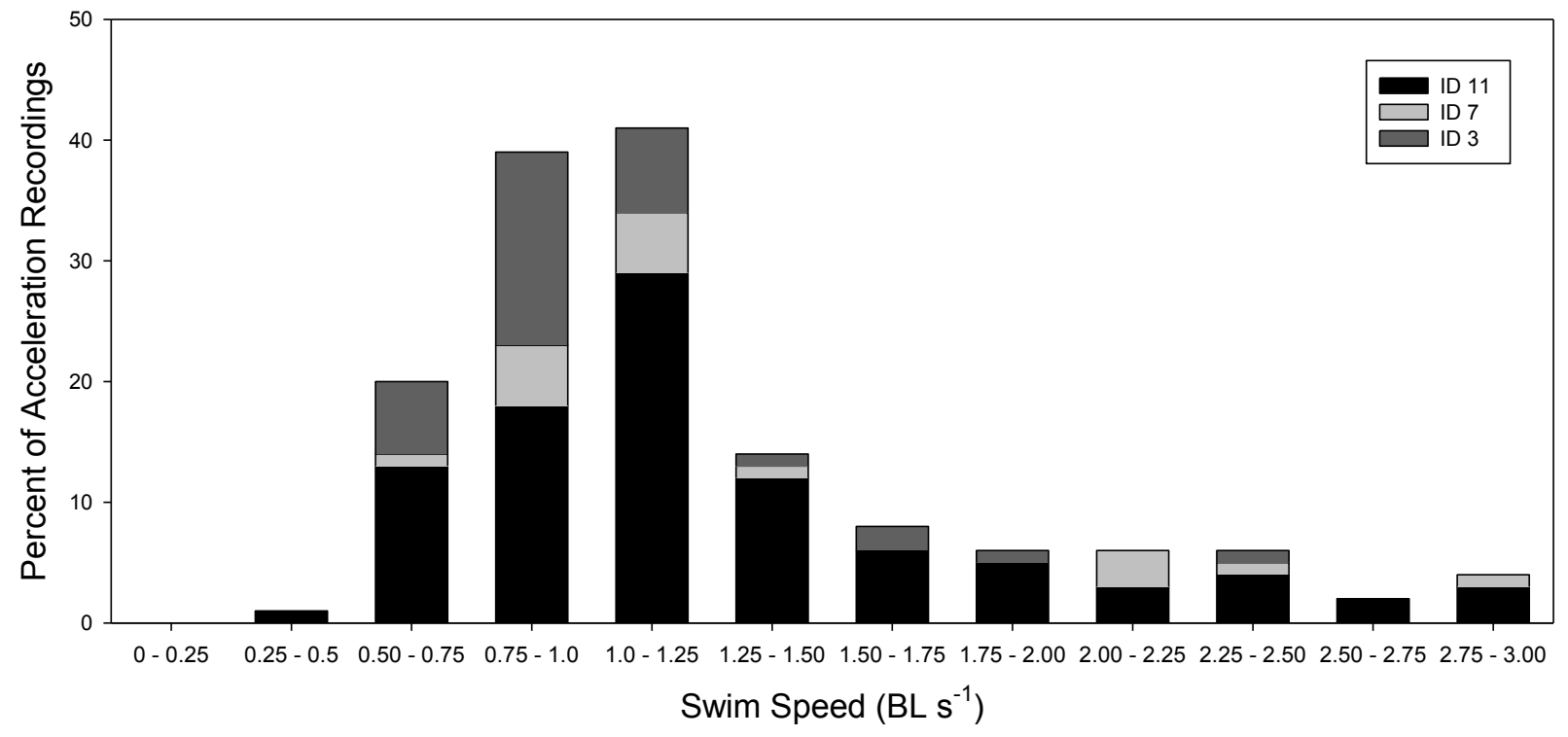

Figure 2-6. Percent of detections at a range of swim speeds for three sockeye salmon released in the Fraser River estuary. Tag IDs were used to identify the proportion of detections from a given fish at each swim speed. Swim speeds determined using relationship between acceleration and swim speed. 


\title{
Chapter 3: Coastal marine and in-river migration behaviour of adult sockeye salmon en route to spawning grounds
}

\begin{abstract}
The reproductive migration of Pacific salmon (Oncorhynchus spp.) is an extremely challenging phase of their life cycle as they navigate from the open ocean through coastal habitats to reach natal streams. Though behaviour and physiology has been studied for the upriver migration, equivalent information for the coastal marine migratory phase has been difficult to obtain. The development of acoustic acceleration transmitters equipped with pressure sensors provided a new tool for the study of swimming activity and migration depth of salmon in both marine and freshwater. Ocean migrating sockeye salmon (O. nerka) bound for the Fraser River, British Columbia were intercepted approximately $200 \mathrm{~km}$ from river entrance, tagged, and tracked as they crossed several acoustic receiver lines in coastal waters and the lower Fraser River. Data from 55 tagged fish revealed that swim speed and depth varied among migratory locales. Interestingly, an index of migration difficulty (i.e., freshwater migration distance and elevation to natal stream) was positively correlated with swim speed in the marine environment. Detailed assessments of individual swim speed and depth patterns revealed a high level of inter-individual variability, though behaviours were remarkably consistent within an individual. Some of the variability in swim speed and depth was explained by diel and tidal cycles. In the marine environment, fish swam at approximately $1.02 \mathrm{BL} \mathrm{s}^{-1}$ $\left(\right.$ range $\left.=0.11-3.62 \mathrm{BL} \mathrm{s}^{-1}, \mathrm{SEM}=0.001\right)$ at an average depth of $13 \mathrm{~m}($ range $=0-171$
\end{abstract}


$\mathrm{m}, \mathrm{SEM}=0.058$ ), whereas the average swim speed in the Fraser River was significantly higher at $1.54 \mathrm{BL} \mathrm{s}^{-1}\left(\right.$ range $\left.=0.54-3.67 \mathrm{BL} \mathrm{s}^{-1}, \mathrm{SEM}=0.001\right)$ at an average depth of $\sim 9$ $\mathrm{m}($ range $=0-21 \mathrm{~m}, \mathrm{SEM}=0.018)$. Consistent with the physiological literature, coastal migrating fish were swimming at metabolically optimal speeds. 


\section{Introduction}

Migration is defined as the synchronous, directional, long-distance movement of a number of individuals of the same species between distinct environments (Endler, 1977; Dingle, 1996). Many of the longest and most challenging migrations are reproductive migrations, whereby individuals migrate great distances to assemble at sites of high quality breeding and rearing habitat. One of the most renowned and remarkable reproductive migrations is that of the semelparous Pacific salmon (Oncorhynchus spp.), which migrate extraordinarily long distances from ocean feeding grounds to their natal freshwater streams to spawn and die.

Of the Pacific salmon, the migration biology of sockeye salmon (Oncorhynchus nerka) is one of the best understood, particularly for sockeye salmon destined for the Fraser River in British Columbia (reviewed in Hinch et al., 2006). Physiological changes and sexual maturation have been observed as far away as $850 \mathrm{~km}$ from the Fraser River (Hinch et al., 2006) and, within $300 \mathrm{~km}$ of the Fraser River, sockeye salmon stop feeding and complete the remaining migration and maturation on endogenous reserves (Hinch et al., 2006). Sockeye salmon encounter many challenges during their migration that can accelerate energy loss, cause physiological stress, impair reproductive maturation, and lead to premature mortality (Hinch et al., 2006). For example, it is well known that high river flows or high temperatures can cause migratory and spawning failure (reviewed in Martins et al., 2012). However, the influence of marine energy use and behaviour on survival of migrating adults is not well known for most Pacific salmon (reviewed in Drenner et al., 2012). 
Previous work tracking adult coastal migrating sockeye salmon has estimated average swim speeds at $\sim 1 \mathrm{BL} \mathrm{s}^{-1}$ for both adults (Madison et al., 1972; Stasko et al., 1976; Quinn, 1988; Crossin et al., 2007) and outmigrating smolts (Welch et al., 2011). Adult sockeye salmon migrating through the Skeena river estuary were manually tracked, and ground speeds were recorded between $0.43-1.42 \mathrm{BL} \mathrm{s}^{-1}$ (Madison et al., 1972). A later study by Stasko et al. (1976) in Haro Strait, found similar trends, with sockeye salmon ground speeds varying between $\sim 0.5-1.5 \mathrm{BL} \mathrm{s}^{-1}$, an observation that was later replicated in the Queen Charlotte Islands, eastern Johnstone Strait and the northern Strait of Georgia by Quinn $(1988,1989)$. Together these studies show that both smolt and adult sockeye salmon swim speeds may be close to $1 \mathrm{BL} \mathrm{s}^{-1}$ but are highly variable, both within an individual and across individuals. More recent studies have calculated ground speed on a much coarser scale, by comparing the time between detections at distant arrays and have found that ground speed estimates are also close to $1 \mathrm{BL} \mathrm{s}^{-1}$ (Crossin et al., 2007). Environmental variables such as diel period and tidal cycle have been used to explain some variability where individuals swim faster during the day and more slowly at night (Madison et al., 1972; Quinn et al., 1989). Physiological variables such as sex hormones, cortisol and gill physiology have also been used to explain variability some of the variability in swim speeds (Cooke et al., 2006; Crossin et al., 2007; Miller et al., 2009). Much of the swim speed variability within the coastal migration phase has yet to be resolved on a fine temporal scale, and is thus difficult to explain.

Once at the Fraser River, sockeye salmon can remain in the Fraser River estuary for several days up to several weeks. Both osmoregulatory changes (through gill $\mathrm{Na} / \mathrm{K}$ 
ATPase expression) and sexual maturity (plasma testosterone concentrations) have been correlated with river entry where individuals that are more sexually mature or are more physiologically prepared for entering freshwater, enter the river earlier compared to less sexually mature individuals or those less physiologically prepared for freshwater (Cooke et al., 2006; Crossin et al., 2007, 2009). Use of tidal flows to assist in migration through the estuary has been previously observed (Levy \& Cadenhead, 1995). In the Fraser River, adult sockeye salmon swim, on average, between $1.0-1.9 \mathrm{BL} \mathrm{s}^{-1}$ depending on sex, river discharge, and water velocity (Rand \& Hinch, 1998; Hinch \& Rand, 1998; Hinch et al., 2004; Hanson et al., 2008). Males have been observed to swim 1.3 times faster than females (118 $\mathrm{cm} \mathrm{s}^{-1}$ compared to $89 \mathrm{~cm} \mathrm{~s}^{-1}$ for females; Hinch \& Rand, 1998), and fish swim more quickly during years of higher river discharge (Hanson et al., 2008), and in river reaches with higher flows (Hinch \& Rand, 1998).

Diel patterns in depth have been observed wherein individuals swim deeper during the day and shallower at night. This phenomenon has been observed in both the open ocean (Ogura \& Ishida, 1995) and freshwater lakes (Newell \& Quinn, 2005; Mathes et al., 2010; Roscoe et al., 2010). However less evidence exists for this 'depth-seeking' behaviour during the coastal migration. Migrating sockeye salmon in Johnstone Strait and the Strait of Georgia (SOG) have been observed to swim in the upper $30 \mathrm{~m}$, above the thermocline and near the halocline, and have been documented undertaking vertical migrations (Quinn et al., 1989). These vertical migrations involve quickly ascending to near surface waters, and then returning to deeper waters and they appear to occur more often at night (Quinn et al., 1989), and are believed to aid in navigation, though whether 
fish are sampling surface waters for olfactory cues, or for other navigational cues, is unknown. Generally, little evidence of 'depth-seeking' behaviours or vertical migrations has been collected for coastally migrating sockeye salmon.

There are $\sim 50$ genetically distinct populations that migrate distances from the ocean to spawning grounds of 50-1150 km (Beacham et al., 2004). Populations differ in adult body morphology and physiology which is thought to be a result of selective pressures exerted by migratory distance and difficulty (Crossin et al., 2004; Cooke et al., 2006; Eliason et al., 2011). For example, coastal populations such as Weaver Creek or Harrison River swim short distances to spawning grounds $(\sim 100 \mathrm{~km})$ and have large robust bodies with low levels of somatic reserve energy. They enter the Fraser River in the fall when water velocity is relatively low. In contrast, upper Fraser populations like Chilko River $(\sim 650 \mathrm{~km})$ have more streamlined bodies and higher somatic energy reserves. They enter the Fraser River in the summer when flows are relatively high and they experience a broader range in water temperatures and more challenging migratory conditions as they must pass through the Hell's Gate rapids, a significant hydrological barrier (Hinch \& Bratty, 2000), and must ascend over 1000 m elevation. Adult Chilko sockeye salmon and other upper river populations are more efficient and better swimmers (i.e., broader aerobic scope, higher burst swim speeds) than coastal populations (Crossin et al., 2004; Eliason et al., 2011). However, studies which have examined marine migration swimming behaviour have generally not examined population-specific differences in swim speeds or behaviours (except see Crossin et al., 2007). 
A number of methods have been used to examine locomotor behaviour, including estimating segment-specific movement rates using mark-recapture techniques with a variety of tag types (Peterson disc, passive acoustic and radio telemetry), and assessing fine-scale continuous movements and rates using active acoustic telemetry (Madison et al., 1972; Stasko et al., 1976; Quinn, 1988), or stationary arrays (English et al., 2005; Crossin et al., 2007). However, these techniques assume that fish swim in a straight line, and do not account for vertical migrations. Thus current estimates of swim speed may be conservative. Swim speeds can be collected using electromyogram (EMG) radio transmitters, which more accurately measure swim speed by assessing tailbeat frequency, rather than inferring swim speed based on time and distance. However, EMG radio transmitters cannot be used in the marine environment as radio signals become attenuated (See Cooke et al., 2004b). Though acoustic EMG transmitters exist (Dewar et al., 1999; Lembo et al., 2008), they have not been widely adopted and challenges remain with electrodes staying fixed in axial musculature over long migrations.

Development of accelerometer technology has provided new tools for studying the behavior of marine animals. For example, in fish, acceleration can be used to derive swim speed principally by measuring acceleration associated with tailbeat oscillations (Shepard et al., 2008). Accelerometer data loggers have been developed to record information on movement (three dimensional (Overall Dynamic Body Acceleration (ODBA)) or two dimensional (Partial Dynamic Body Acceleration (PDBA)) acceleration (Shepard et al., 2008) in a wide range of taxa (e.g. humans: Halsey et al., 2008, birds: Wilson et al., 2006, Green et al., 2009), including fishes (sharks: Gleiss et al., 2010, 
salmon: Clark et al., 2010, bonefish: Brownscombe et al., 2013). However, as with all loggers, they have limited applicability for use in a natural environment where it is more difficult to retrieve loggers (Cooke et al., 2004b). More recently, acoustic transmitters have been developed that measure acceleration in three axes and then transmit an average value to a receiver. These transmitters can also be fitted with pressure or temperature sensors so information on depth can be collected. This technology has been used to monitor fine-scale movement patterns in great barracuda, Sphyraena barracuda (O'Toole et al., 2010) and estimate energy use of bonefish, Albula vulpes (Murchie et al., 2011), and cuttlefish, Sepia apama (Payne et al., 2011). Relationships between acoustic acceleration transmitter output and swim speed have recently been developed for sockeye salmon in laboratory respirometers (Wilson et al., 2013), enabling swimming speeds to be estimated for tagged free swimming sockeye salmon.

In this paper, I use acceleration transmitters to characterize swimming behaviour of adult sockeye salmon as they migrate through a coastal portion of the marine migration phase, through the estuary and into the lower reaches of the Fraser River. I predicted that swim speeds would be slower in the marine environment than in the river, as river flows should force fish to swim more quickly, and speeds may be influenced by the diel cycle. I also predicted that migration depth would be fairly consistent in the marine environment, with some vertical migrations, as has been seen in previous work in the SOG (Quinn et al., 1989). Finally, I predicted that swim speeds in the marine environment would differ based on migration difficulty (e.g., migration distance multiplied by migration elevation in freshwater), an index that has shown to reflect swim speeds in the Fraser River 
(Crossin et al., 2004; Eliason et al., 2011). I expected that fish with more difficult freshwater migrations would swim faster than fish with shorter freshwater migrations, as fish with difficult migrations are typically better swimmers (Crossin et al., 2004; Eliason et al., 2011).

\section{Methods}

\section{Field Site/ Receiver Arrays}

The following study was conducted in accordance with University of British Columbia Animal Care Committee and guidelines of the Canadian Council of Animal Care, as administered by Carleton University (Animal Care \# B10-08) and the University of British Columbia (Animal Care \# A11-0215). Fifty-five sockeye salmon (fork length $(\mathrm{FL})=51-70 \mathrm{~cm})$ were caught by troll fishing in Rock Bay, Johnstone Strait $\left(50^{\circ} 20^{\prime} \mathrm{N}\right.$, $125^{\circ} 25^{\prime} \mathrm{W}$; Fig. 1) throughout August $7^{\text {th }}-17^{\text {th }}, 2012$ (surface water temperature $=10-13$ $\left.{ }^{\circ} \mathrm{C}\right)$. Once captured, fish were placed in a large flow through tank and the hook was removed. No more than 12 fish were held in the tank at any time. Fish were individually dip netted out of the tank and placed in a V-shaped foam lined trough, which was continuously refreshed with seawater. Fork length of fish was measured and a tissue $(<$ $0.1 \mathrm{~g})$ biopsy from the adipose fin was collected for population identification and stored at room temperature in $95 \%$ ethanol. The population of each sockeye salmon was identified using DNA analyses (Beacham et al., 1995, 2004). Tagging and biopsy samples were collected using protocols for the nonlethal anaesthetized sampling of sockeye salmon (see Cooke et al., 2005, 2006). A previous study by Cooke et al. (2005) showed that there were no differences in behavior or survivorship between tagged fish 
that were biopsied or not biopsied (Cooke et al., 2005). An acceleration transmitter (VEMCO, Halifax, NS. Model V13AP-1H, $69 \mathrm{kHz}, 16 \mathrm{~mm}$ x $67 \mathrm{~mm}$ ) was then gastrically inserted (Cooke et al., 2005). Accelerometers measured acceleration in three axes, for $10 \mathrm{sec}$ with a sampling frequency of $10 \mathrm{~Hz}$. The root mean square (RMS) acceleration was calculated by averaging acceleration in all three dimensions using equation; RMS $=\left(\mathrm{X}^{2}+\mathrm{Y}^{2}+\mathrm{Z}^{2}\right)^{0.5}$. The V13AP tags transmitted every 20-70 sec, alternating between acceleration and depth (in $\mathrm{m}$ ), with a 3:1 ratio (i.e., A-A-A-D).

Once tagging was completed, fish were returned to the tank and transported to one of two release sites. Four acoustic receivers were set up $\sim 10 \mathrm{~km}$ south of release sites (Seymour Narrows; Fig. 3-1). Further south of those acoustic receivers $(\sim 70 \mathrm{~km})$, fish passed the northern Strait of Georgia (NSOG) line. Fish were next detected by receivers deployed throughout lower Fraser River ( 200 km from NSOG; Fig. 3-1).

\section{Statistical Analyses}

DNA analysis identified 11 Fraser River populations amongst the tagged salmon: Chilko, Stellako, Lower Adams, North Thompson, Bowron, Gates Creek, Weaver, Birkenhead, Harrison, Pitt River, Early Stuart and 1 non-Fraser River population; Klinaklini (B.C. mainland population). Fraser River populations can be classified into run timing groups based on date of river entrance (Table 3-1). These populations can also be categorized based on the difficulty of their migration. There have been several 'migration difficulty indices' developed that involve migratory distance, elevation, temperature or combinations of these variables, and have been used to compare freshwater migration behaviour among populations of Fraser River sockeye salmon (e.g. 
Crossin et al., 2004; Eliason et al., 2011). We chose to use the one recommended by Crossin et al. (2004) which is based on 'work' defined as the distance of upriver migration to the home stream multiplied by the elevation gained multiplied by 0.001 . Work represents the slope of migration where the higher the value the more difficult the migration. This resulted in values between 1-1000. Migratory 'work' was classified into three categories of migration difficulty: values $<100$ as easy migrations, value between $100-200$ as intermediate, and values $>200$ as difficult (Table 3-1).

For purposes of this study we define swim speed as the fish movement calculated from RMS acceleration (which reflects tailbeat oscillations). Ground speed, was calculated based on time and distance between detections, and reflects a simple single vector trajectory of fish swimming based on distance travelled rather than tailbeat frequency. Tidal information was collected from DFO open access website.

Statistical analyses were done using R 2.15.306 (R Development Core Team, 2012) with 'nlme' (Pinheiro et al., 2013), 'AICcmodavg' (Mazerolle, 2012), and 'multcomp' (Hothorn et al., 2008) packages. Data were tested for normality and homoscedasticity. Data failing homoscedasticity were square root transformed. Mixed effect models were used to determine how time to first detection at array, migration speed, migration depth, swim speed (response variables) were influenced by tide, diel period, location, and (due to colinearity) one of migration difficulty index, run timing group or population as predictor variables. All two-term interactions were included as potential explanatory variables. In addition, all models contained fish ID as a random variable to account for repeated detections for each fish. The most parsimonious model 
for each response variable was chosen with a stepwise procedure based on minimizing the bias-corrected Akaike Information Criterion (AICc) (Burnham \& Anderson, 2002). Bonferroni post hoc tests with planned comparisons were used to examine differences in response variables across locations and within locations across migration difficulty index. Each fish was ranked by its swim speed relative to all other fish at each detection site, and subsequent Spearman's rank order correlation test was used to determine interindividual variability in swim speed. Significance levels for all tests were $\alpha=0.05$.

\section{Results}

Swim speeds (i.e., measured using the accelerometer data) were greater in the Fraser River and lower in the marine environment (Fraser River 1.54 BL s ${ }^{-1}$; marine 1.01 BL $\left.\mathrm{s}^{-1}, \mathrm{p}<0.001\right)$. The mixed effect model for swim speed selected by AICc included environment (marine/river), tide and diel period. Within the marine areas, swim speed was higher in Seymour Narrows than in the NSOG (Fig. 3-2A). The most parsimonious $(\triangle \mathrm{AICc}=0)$ mixed effect model for swim speed included tide, diel period and an interaction between location and migration index. Bonferroni post-hoc planned contrasts comparing swim speed between migration difficulty categories within each location showed that fish with easy freshwater migrations swam significantly slower than fish with difficult migrations at NSOG $\left(0.42 \mathrm{BL} \mathrm{s}^{-1}\right.$ vs. $\left.1.52 \mathrm{BL} \mathrm{s}^{-1}, \mathrm{z}=3.27, \mathrm{p}=0.022\right)$ but not different than fish with intermediate difficulty migrations $\left(0.42 \mathrm{BL} \mathrm{s}^{-1}\right.$ vs. $0.99 \mathrm{BL} \mathrm{s}^{-1}, \mathrm{z}=$ 2.48, $\mathrm{p}=0.272$ ). The same was true in the Fraser River; fish with easy freshwater migrations swam more slowly than fish with difficult migrations $\left(1.51 \mathrm{BL} \mathrm{s}^{-1}\right.$ vs. $1.82 \mathrm{BL}$ $\left.\mathrm{s}^{-1}, \mathrm{z}=3.60, \mathrm{p}=0.006\right)$ but not differently than fish with intermediate migrations $(1.51 \mathrm{BL}$ 
$\mathrm{s}^{-1}$ vs. $\left.1.73 \mathrm{BL} \mathrm{s}^{-1}, \mathrm{z}=2.64, \mathrm{p}=0.172\right)$. No differences in swim speeds were observed between any of the three migration difficulty categories at Seymour Narrows (difficult vs. easy $\mathrm{z}=-1.53, \mathrm{p}=1.00$; easy vs. intermediate $\mathrm{z}=-0.20, \mathrm{p}=1.00$; difficult vs. intermediate $\mathrm{z}=-1.61, \mathrm{p}=1.00$ ) or river entrance (difficult vs. easy $\mathrm{z}=2.64, \mathrm{p}=0.172$; easy vs. intermediate $z=0.93, p=1.00$; difficult vs. intermediate $z=2.00, p=0.946$ ).

Planned contrasts of each migration difficulty category across locations showed that fish with difficult freshwater migrations had swim speeds that were significantly higher in NSOG than in Seymour Narrows $(\mathrm{z}=-4.87, \mathrm{p}<0.0001)$, significantly higher at river entrance compared to NSOG $(\mathrm{z}=-13.84, \mathrm{p}<0.0001)$ and highest in the river compared to river entrance $(\mathrm{z}=-9.00, \mathrm{p}<0.0001)$. Fish with intermediate and easy freshwater migrations swam more slowly in NSOG than in Seymour Narrows $(z=5.67$, $\mathrm{p}<0.0001 ; \mathrm{z}=17.90, \mathrm{p}<0.0001$, respectively), faster in the river entrance array compared to NSOG ( $\mathrm{z}=-4.95, \mathrm{p}<0.0001 ; \mathrm{z}=-10.38, \mathrm{p}<0.0001$, respectively) and the fastest in the river $(\mathrm{z}=-9.87, \mathrm{p}<0.0001 ;-0.58, \mathrm{p}<0.0001$, respectively). Interestingly, despite having significantly lower mean swim speeds, the range of swim speeds was broadest in the marine environment (Seymour Narrows and NSOG) and narrower in the Fraser River (Table 3-2). Faster swim speeds were associated with a decrease in time spent in each array (Table 3-2), but not with time to arrival at each array.

Fish from all three migration groups reached the Seymour Narrows and NSOG arrays in same amount of time after release. However, fish from the intermediate freshwater migration difficulty category took longer to arrive at the river entrance array (Fig. 3-2B). Ground speed (the distance between arrays divided by the time it took to 
swim between arrays) was compared with swim speeds calculated from accelerometers. Post hoc Bonferroni planned comparisons of the mixed effect model of location and speed estimate (ground speed vs. swim speed) showed that only in-river estimates of swim speed were significantly higher than ground speed $(z=6.55, p<0.0001$; Fig. 3-3A). Spearman rank order correlation was significant across all consecutive locations (Seymour Narrows - NSOG: $r h o=0.46, \mathrm{~s}=610, \mathrm{p}=0.47$; NSOG - River: $\mathrm{rho}=0.77, \mathrm{~s}=158$, $\mathrm{p}=0.0008$; River - In river: rho $=0.75, \mathrm{~s}=116, \mathrm{p}=0.003$; Fig. 3-3B). Furthermore, traces of three fish swimming at each location demonstrate that swimming was different between individuals but steady with little intra-individual variability (Fig. 3-4).

The most parsimonious model for describing depth (chosen by AICc) was found to include diel period and an interaction between location and migration difficulty category. Planned contrasts within each array showed that fish with easy freshwater migrations swam significantly deeper in Seymour Narrows than fish with difficult freshwater migrations ( $52.1 \mathrm{~m}$ vs. $12.3 \mathrm{~m}, \mathrm{z}=-4.51, \mathrm{p}=0.0001)$ and intermediate difficulty freshwater migrations (52.1 m vs. $16.4 \mathrm{~m}, \mathrm{z}=-4.38, \mathrm{p}=0.0002)$. Fish from all three freshwater migration difficulty categories swam at the same depth within NSOG, river entrance, and in-river arrays (Fig. 3-5). Planned contrasts were also conducted comparing each migration difficulty category across all array sites. Fish with easy and difficult freshwater migrations swam deeper in Seymour Narrows than in NSOG (Easy: $z=19.52$, $\mathrm{p}<0.0001$; Difficult: $\mathrm{z}=3.86, \mathrm{p}<0.002$ ) but no difference in swimming depth between Seymour Narrows and NSOG occurred for fish with intermediate difficulty freshwater migrations $(\mathrm{z}=2.08, \mathrm{p}=0.794)$. Fish with easy freshwater migrations swam shallower at 
river entrance than at NSOG $(\mathrm{z}=6.21, \mathrm{p}<0.0001)$ but fish with intermediate and difficult freshwater migrations swam at similar depths $(\mathrm{z}=1.82, \mathrm{p}=1.00$ vs. $\mathrm{z}=-2.19, \mathrm{p}=0.600)$. Once in-river, all fish swam at similar depths (Fig. 3-5).

Range of depth detections was the greatest in Seymour Narrows $(0-171.9 \mathrm{~m})$, and lower at NSOG $(0-61.9 \mathrm{~m}$; Table $3-2)$. In the river, range of migration depth was similar at both river entrance $(0-20.9 \mathrm{~m})$ and in river arrays $(0-16.4 \mathrm{~m}$; Table $3-2)$. Detections of fish $<2 \mathrm{~m}$ from the surface were considered vertical migrations, given tags had error range of $\pm 2.5 \mathrm{~m}$. Vertical migrations, in percentage of detections $<2 \mathrm{~m}$ at a receiver array, were highest in Seymour Narrows (42\%), lower for NSOG and river entrance $(17 \%)$ and the lowest in river (7\%). Example of traces of fish migration depths were reported over a 25 min continuous period of transmitted fish depth information (Fig. 3-6).

\section{Discussion}

Estimates of swim speeds based on transmitted accelerometer information was consistent with and supported conclusions found using more traditional methods, and, they also provided new insights into swim speeds and behaviours on a finer temporal scale than has been previously possible. I found that swim speeds in the marine environment (Seymour Narrows and NSOG) were slower than in the river, supporting my prediction that river swim speed would increase in response to the increase in water velocity. Variability in swim speeds was also related to diel period, where fish swam slightly faster during the day, concurrent with the findings of Madison et al. (1972). In their study, diel period strongly influenced swim speeds likely because their fish were 
staging for river entrance into the Skeena River, rather than in SOG or entering the turbid Fraser River. Tide was a significant, albeit minor, predictor of swim speed which was not surprising as Stasko et al. (1976) found that despite the strong tidal influence of the coastal migration routes, salmon did not use tidal currents, but rather swam in a directed route independent of flow.

During the marine portion of migration, tagged adult sockeye salmon swam the fastest in the Seymour Narrows array, compared with the NSOG. Seymour Narrows is the narrowest portion of Johnstone Strait and tidal currents are much stronger than in other regions. The higher swimming speeds relative to NSOG were therefore, not surprising. We anticipated that swim speeds through other regions of Johnstone Strait would be higher than NSOG as well because of the generally higher tidal currents in the Strait. Swim speeds in NSOG were close to $1 \mathrm{BL} \mathrm{s}^{-1}$, which supports previous estimates of swim speed for that region reported for both adults (Quinn, 1988; Quinn et al., 1989; Crossin et al., 2007) and smolts (Welch et al., 2011). Swim speeds in the river were higher than in the marine environment, and highest in the in-river array, away from tidal influence. Previous studies have shown that salmon use tidal flows to assist in migration through the estuary (Levy \& Cadenhead, 1995). However, tidal-mediated swimming speeds were not observed in my study.

Swim speeds through the in-river array were $1.7 \mathrm{BL} \mathrm{s}^{-1}$ on average, which was similar to swim speeds calculated from electromyogram (EMG) telemetry observations in more upstream regions of the river (Table 3-2; Hinch \& Rand, 1998). In EMG-based river studies, swim speed largely depended on sex, river discharge, and water velocity, 
with males swimming 1.3 times faster than females (Hinch \& Rand, 1998), fish swimming faster during years of higher river discharge (Hinch \& Rand, 2000), and faster through river reaches with higher water velocities (Hinch \& Rand, 1998). The in-river array used in this study was approximately $100 \mathrm{~km}$ downstream of where the previous EMG estimates of swim speeds were collected, thus suggesting that fish swim speeds were relatively consistent throughout the lower Fraser River.

Sockeye salmon populations have different physiological adaptations to cope with their different freshwater migratory experiences (Crossin et al., 2004; Eliason et al., 2011). With telemetry Crossin et al. (2007) observed population-specific differences in marine and lower Fraser River travel speeds. While studies generally make comparisons among populations or run-timing groups, we discovered that freshwater migration difficulty, rather than population or run-timing group, was a better predictor of marine swimming behaviour. Thus adaptations that contributed to differences among populations in swim performance and energy conservation during Fraser River migrations (Crossin et al., 2004, Eliason et al. 2011) appeared to also be influential for migrations in the marine environment. These findings are the first evidence in anadromous fish that marine swim speeds are influenced by physiological, morphological and behavioural traits important for successful completion of freshwater migrations.

In the vicinity of the NSOG array, fish with easy freshwater migrations swam significantly slower than fish with intermediate or difficult freshwater migrations, both of which pass Hell's Gate (a significant migratory challenge). Evidence of differences in migratory behaviour extended into the river, as individuals with easier migrations swam 
more slowly in the river (Fig. 3-2A). Interestingly, though fish with easy freshwater migrations swam the slowest, fish with intermediate migrations entered the river later than fish with easy or difficult migrations. The time taken to arrive at both Seymour Narrows and NSOG receiver arrays was similar between groups, so swim speed alone cannot explain the discrepancies in arrival at the river entrance array. Fish with easy freshwater migrations swam slower than those with intermediate or difficult freshwater migrations, thus I would expect them to take the longest to arrive at the river entrance array. However, fish with intermediate difficulty freshwater migrations took the longest. Either fish with these migrations swam slower after NSOG (where there are no receivers) or, more likely, these fish held outside of the mouth of the Fraser River; a phenomenon that has been previously observed (Cooke et al., 2004; Crossin et al., 2007).

Traditionally, ground speeds in the Strait of Georgia have been estimated by dividing the distance between detections by the elapsed time between detections (English et al., 2005; Crossin et al., 2007, 2009). This method assumed that fish swam in a straight line and did not account for differences in swim speed due to tidal influence and currents. I calculated ground speed and compared it to swim speeds calculated from accelerometer output and found that at marine sites (Seymour Narrows and NSOG), swim speed was not different from ground speed. This demonstrated that sockeye salmon migrate in a very directed manner, with few deviations. Once in the river, swim speed was much faster than ground speed, which was expected since fish were swimming against strong river currents. This method also showed that swim speeds within the Strait of Georgia were close to $1 \mathrm{BL} \mathrm{s}^{-1}$, consistent with previous measurements of ground speed in Strait of Georgia (Quinn, 1988, Quinn et al., 1989; Crossin et al., 2007), as well as fish 
manually tracked in the Skeena River Estuary (Madison et al., 1972) and Haro Strait (Stasko et al., 1976).

Each individual's swim speed was generally consistent across sites. Fish that swam faster relative to others at Seymour Narrows, generally swam faster throughout marine coastal and in-river migration. Hanson et al. (2008) found that ground speed was not consistent within individuals or in areas of complex flows, though this study was further up-river $(\sim 100 \mathrm{~km})$ than the current study. English et al. (2005) showed that swim speeds appeared to be consistent within an individual once fish had reached the Thompson River ( $300 \mathrm{~km}$ for Fraser River mouth). These data showed that swim speeds were repeatable throughout ocean migration and into the farthest downstream reaches of the Fraser River. Inter-individual variability has often been observed in salmon, where some individuals swam more aggressively, while others tended to follow microcurrents (Stasko et al., 1976). Physiology has been used to explain some of this inter-individual variability (Hinch \& Rand, 1998; Crossin et al., 2007; Hanson et al., 2008). This variability was observed directly, within this study, and was observed in the traces of three representative swimming sockeye salmon. Generally, traces of swim speeds at receiver sites showed that within an individual, swim speeds appeared consistent, with only $5 \%$ of detections exceeding $2.5 \mathrm{BL} \mathrm{s}^{-1}$. This was similar to a study by Quinn (1988) where he observed sockeye salmon swimming consistently, with $17 \%$ of detections at what he considered 'bursting speeds'. The speed and consistency of swimming at $1 \mathrm{BL} \mathrm{s}^{-1}$ supports previous work that salmon swim to minimize energetic costs by swimming at close to optimal swim speed (Brett, 1995). 
The most parsimonious mixed effect model showed that diel period influenced migration depth. In Seymour Narrows, migration depth exhibited strong diel patterns, where fish swam much deeper during the day. However, this was not observed throughout the rest of migration. Fish swam the deepest in Seymour Narrows, which had generally greater water depths and was a more tidally influenced region compared to the rest of the coastal migration (250 m water depths in some areas, compared to an average of $150 \mathrm{~m}$ in NSOG). Fish arrived $<24 \mathrm{~h}$ after release on the Seymour Narrows array, suggesting that short-term tagging effects may have influenced depth. However, previous studies have shown that tagging does not appear to affect behaviour (Davidsen et al., 2013). This area also had more marine predators, so the depth-seeking behaviour may have represented an anti-predation mechanism. Fish in the NSOG, river entrance and inriver arrays had similar migration depths $(8-12 \mathrm{~m})$. The relative difficulty implied by the migration index was also a predictor of migration depth, where fish with easy and difficult migrations swam the deepest in Seymour Narrows and NSOG, compared to fish with intermediate migrations. Similar to swim speed, migration depth varied considerably between individuals. Interestingly, depth traces showed that fish swam more closely to the surface than previous studies, which found that sockeye salmon swam in upper $30 \mathrm{~m}$ but avoided warm surface waters (Quinn et al., 1989). Vertical migrations were defined as the fish occupying $<2 \mathrm{~m}$ from surface since tags are accurate to within $\pm 2.5 \mathrm{~m}$. Frequent vertical migrations were observed with fewer vertical migrations closer to the Fraser River. Frequent vertical migrations have previously been reported in sockeye salmon (Quinn et al., 1989). This behaviour is believed to aid in navigation, though whether fish are sampling surface waters for olfactory cues or seeking other 
navigational cues is unknown. Thus decreased frequency of vertical migrations with decreased distance to the Fraser River could be due to increased strength of navigational cues. Alternatively, fish may have been actively avoiding predators in Seymour Narrows. In the river, fewer vertical migrations may have been a result of habitat selection since current are faster near the surface, and thus would have required more energy to swim at the surface.

It is important to note that the model used to calculate swim speed from acceleration output has some limitations. Swim speed was determined from RMS acceleration using a previously developed model (Wilson et al., 2013). This model was developed in fresh water and as there is a slight difference in density between fresh water and saltwater that may result in some error in swim speed calculations. The accelerometer measures acceleration, mostly driven by tailbeat frequency. Thus actual swim speeds may have been slightly slower than calculated, but given variability in swim speed, such a bias would have probably been very modest and not influence overall patterns of swim speed. The equation is accurate only within the range $0.5-2.5 \mathrm{BL} \mathrm{s}^{-1}$. Approximately $95-98 \%$ of detections at each site fell within the calibrated range of the swim speed model. Therefore, I believe the data generated from the model and presented here are an accurate representation of the majority of swim speeds exhibited by migrating sockeye salmon. Acknowledging the limitations of the swim speed calculations, this study is the first to directly examine swimming patterns of sockeye salmon throughout the coastal phase of adult migration. 
The swim speed estimates determined in this study were comparable to estimates of swim speed from other more traditional methods (i.e., acoustic, disc, radio) showing that sockeye salmon swam at $\sim 1 \mathrm{BL} \mathrm{s}^{-1}$ in the Strait of Georgia. However, use of measurements of swim speed from accelerometers yielded more insight into individual variability, and population differences for a hitherto poorly described region (coastal transition zone). In more constricted areas such as Johnstone Strait and the Fraser River, salmon swam faster due to increased water velocity. This study also supported previous work that suggested sockeye salmon swim in a directed route, with little deviation throughout the coastal approach, until fish reach the mouth of the Fraser River. The overall difficulty of the freshwater migration of a given population was an important predictor of both swim speed and migration depth for individuals and, thus, presumably populations. In the future, this work could be expanded to increase sample sizes and further examine why differences in swimming speed relative to migration difficulty exist (i.e., physiology) and look at success (i.e., survival to spawning grounds). Finally, I found that individual swim speeds were consistent between sites, but significant inter-individual variance in swim speed and migration depth remains unexplained. Future work should examine swim speed in the context of energy use in coastal migration and how this influences survival and reproductive investment. This represents the first study to use accelerometers to measure swim speed in both the marine and freshwater environments. 


\section{Tables}

Table 3-1. Acoustic acceleration transmitters deployed in sockeye salmon and migratory characteristics of the populations.

\begin{tabular}{|c|c|c|c|c|c|c|}
\hline Run Difficulty & $\begin{array}{l}\text { Run Timing } \\
\text { Group }\end{array}$ & Population & $\begin{array}{l}\text { Migratory distance } \\
\left(E_{M}\right)(\mathrm{km})\end{array}$ & $\begin{array}{l}\text { Migratory elevation } \\
\left(\mathrm{D}_{\mathrm{M}}\right)(\mathrm{m})\end{array}$ & $\begin{array}{l}\text { Work } \\
\left(0.001 \mathrm{E}_{\mathrm{M}} \mathrm{D}_{\mathrm{M}}\right)\end{array}$ & $\begin{array}{l}\text { Number } \\
\text { Tagged }\end{array}$ \\
\hline \multirow[t]{4}{*}{ Difficult } & Summer & Chilko & 642 & 1174 & 753 & 26 \\
\hline & Summer & Stellako & 958 & 677 & 649 & 3 \\
\hline & Early Stuart & Early Stuart & 1071 & 690 & 734 & 2 \\
\hline & Early Summer & Bowron & 1055 & 956 & 1009 & 1 \\
\hline \multirow[t]{4}{*}{ Intermediate } & Early Summer & North Thompson & 408 & 373 & 152 & 7 \\
\hline & Early Summer & Gates Creek & 364 & 280 & 102 & 4 \\
\hline & Late & Lower Adams & 480 & 346 & 166 & 1 \\
\hline & Late & Birkenhead & 268 & 495 & 133 & 2 \\
\hline \multirow[t]{4}{*}{ Easy } & Late & Weaver & 117 & 32 & 4 & 6 \\
\hline & Late & Harrison & 121 & 10 & 1 & 1 \\
\hline & Early Summer & Pitt River & 78 & 10 & 1 & 1 \\
\hline & Other & Klinaklini & $\mathrm{N} / \mathrm{A}$ & $\mathrm{N} / \mathrm{A}$ & $\mathrm{N} / \mathrm{A}$ & 1 \\
\hline
\end{tabular}


Table 3-2. Summary of swimming behaviour for tagged sockeye salmon.

\begin{tabular}{|c|c|c|c|c|}
\hline & $\begin{array}{l}\text { Seymour } \\
\text { Narrows }\end{array}$ & NSOG & River Entrance & In River \\
\hline Number of Fish detected & $\begin{array}{l}27 \\
(14,8,5)\end{array}$ & $\begin{array}{l}26 \\
(14,7,5)\end{array}$ & $\begin{array}{l}16 \\
(9,4,3)\end{array}$ & $\begin{array}{l}14 \\
(8,4,2)\end{array}$ \\
\hline $\begin{array}{l}\text { Time spent in array } \\
\text { (hrs) }\end{array}$ & $\begin{array}{l}9.4 \\
(11.6,7.5,6.5)\end{array}$ & $\begin{array}{l}4.3 \\
(1.5,7.9,6.9)\end{array}$ & $\begin{array}{l}10.2 \\
(9.4,10.5,11.9)\end{array}$ & $\begin{array}{l}14.2 \\
(14.0,13.1,17.7)\end{array}$ \\
\hline $\begin{array}{l}\text { Distance from release } \\
(\mathrm{km})\end{array}$ & 10 & 70 & 200 & 250 \\
\hline $\begin{array}{l}\text { Migration Speed } \\
\left(\mathrm{BLs}^{-1}\right)\end{array}$ & $\mathrm{n} / \mathrm{a}$ & 1.10 & 1.02 & 1.29 \\
\hline $\begin{array}{l}\text { Mean Swim Speed } \\
\left(\mathrm{BLs}^{-1}\right)\end{array}$ & $\begin{array}{l}1.23 \\
(1.35,1.34,0.99)\end{array}$ & $\begin{array}{l}0.98 \\
(1.52,0.99,0.42)\end{array}$ & $\begin{array}{l}1.41 \\
(1.53,1.22,1.47)\end{array}$ & $\begin{array}{l}1.69 \\
(1.82,1.73,1.51)\end{array}$ \\
\hline $\begin{array}{l}\text { Range of Swim Speeds } \\
\left(\mathrm{BLs}^{-1}\right)\end{array}$ & $0.20-3.62$ & $0.11-3.30$ & $0.54-3.33$ & $0.83-3.67$ \\
\hline $\begin{array}{l}\text { Mean depth } \\
\text { (m) }\end{array}$ & $\begin{array}{l}26.9 \\
(12.3,52.1,16.4)\end{array}$ & $\begin{array}{l}9.2 \\
(7.3,7.7,12.7)\end{array}$ & $\begin{array}{l}8.0 \\
(8.5,6.1,9.5)\end{array}$ & $\begin{array}{l}8.9 \\
(8.5,9.9,8.2)\end{array}$ \\
\hline $\begin{array}{l}\text { Range of depths } \\
\text { (m) }\end{array}$ & $0-171.9$ & $0-61.9$ & $0-20.9$ & $0.9-16.4$ \\
\hline $\begin{array}{l}\text { Vertical Migrations } \\
(\% \text { of detections }<2 \mathrm{~m})\end{array}$ & $\begin{array}{l}42 \\
(45,48,33)\end{array}$ & $\begin{array}{l}17 \\
(28,14,9)\end{array}$ & $\begin{array}{l}17 \\
(12,29,9)\end{array}$ & $\begin{array}{l}7 \\
(9,2,10)\end{array}$ \\
\hline
\end{tabular}

*Migration speed was determined by dividing distance and time between successive arrays. Tabulated values show means for all individuals, as well as by migration difficulty index (Values in brackets; Difficult, Intermediate, Easy, respectively). Tag losses may be due to capture in fisheries (two tags were reported captured by local fishermen), or by marine predators. 


\section{Figures}

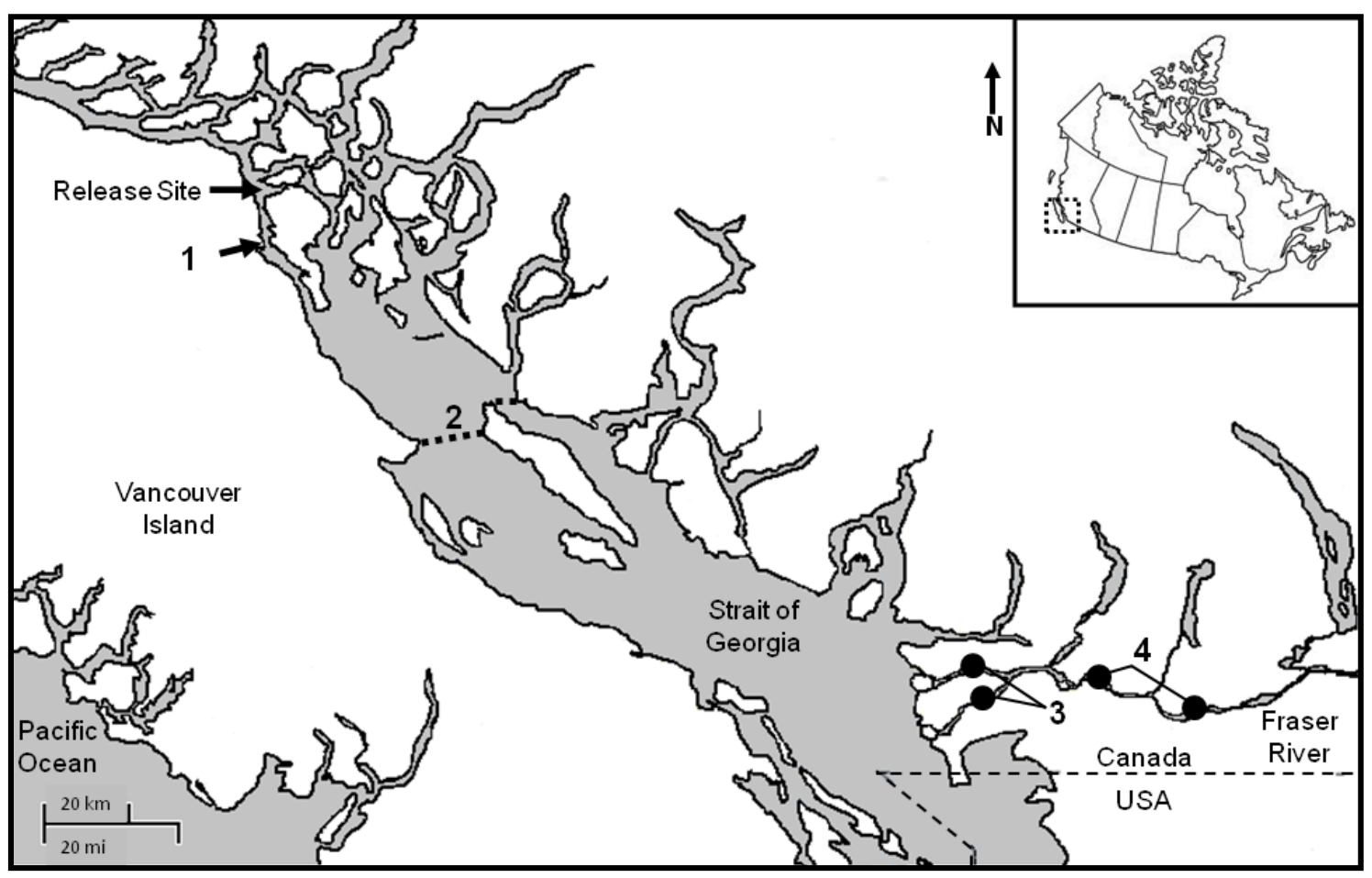

Figure 3-1. Map of acoustic receiver arrays throughout SOG and lower Fraser

River. (1-Seymour Narrows, 2-Northern Strait of Georgia (NSOG), 3-River

Entrance, 4-In River). Sockeye salmon were captured by trolling and released in Rock Bay. 


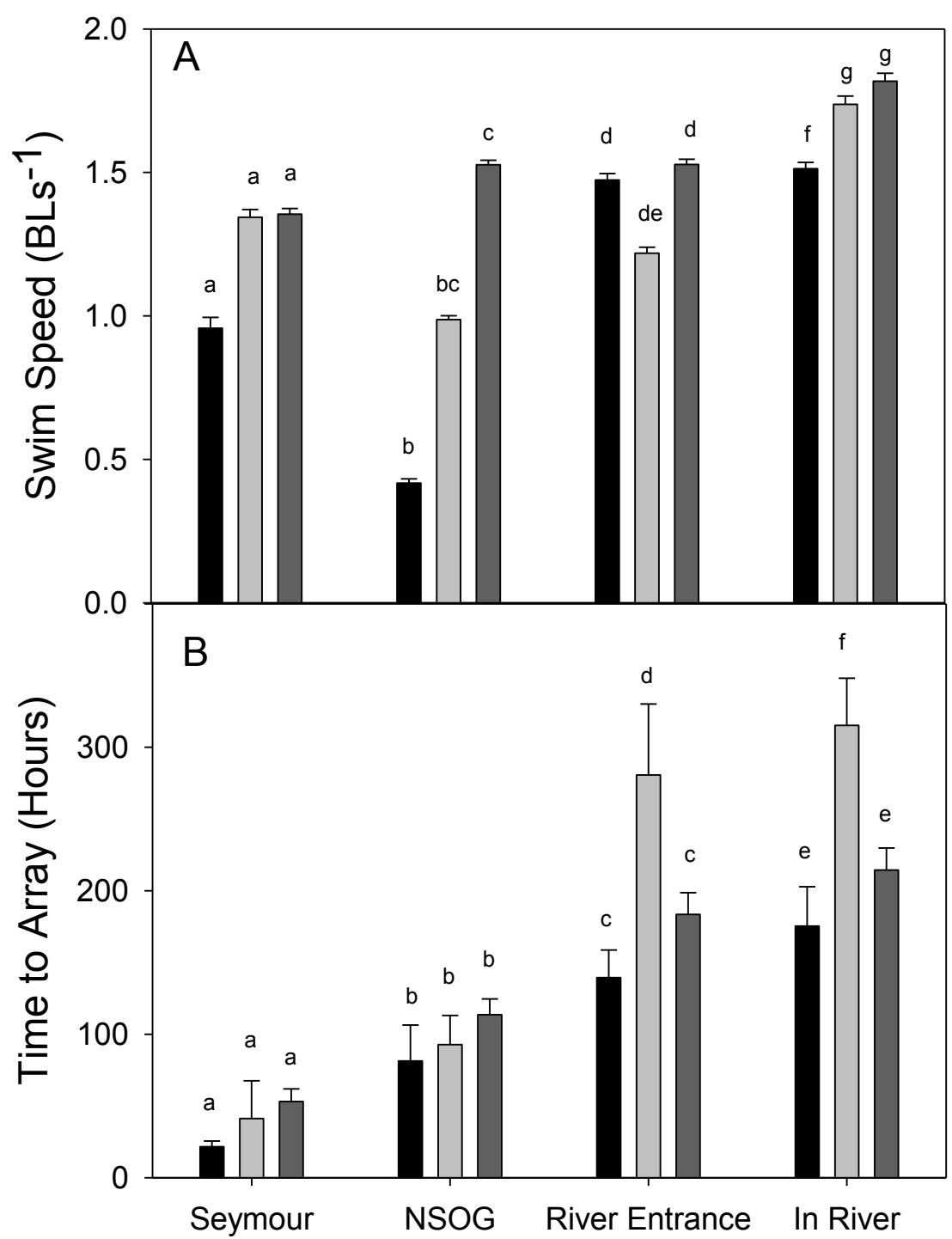

Figure 3-2. Behavioural trait characterized for each migration difficulty index at each receiver array; A) swim speed B) timing to first detection (release to 1, 1-2, etc). Easy migrations are represented in black, intermediate in dark grey and difficult in light grey. Error bars represent SEM. Letters represent significant differences between migration difficulty groups $\alpha=0.05$. 


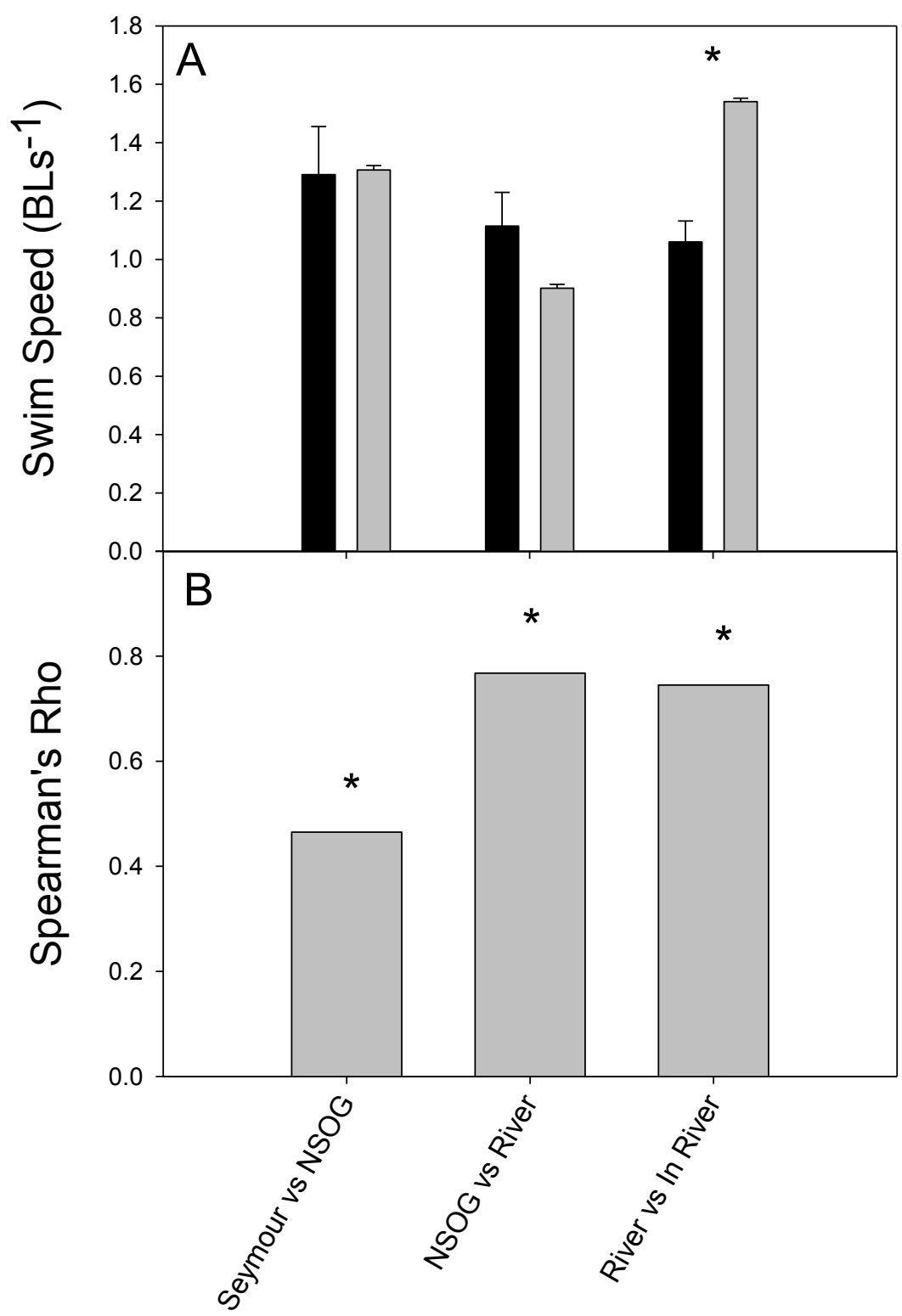

Figure 3-3. Comparison between A) ground speed and swim speed calculated using acceleration transmitters and B) repeatability of swim speeds between Seymour Narrows and NSOG, NSOG and river entrance and river entrance and in-river arrays. Ground speed represented in black and swim speed in grey. Asterisk represents significance where $\alpha=0.05$. 


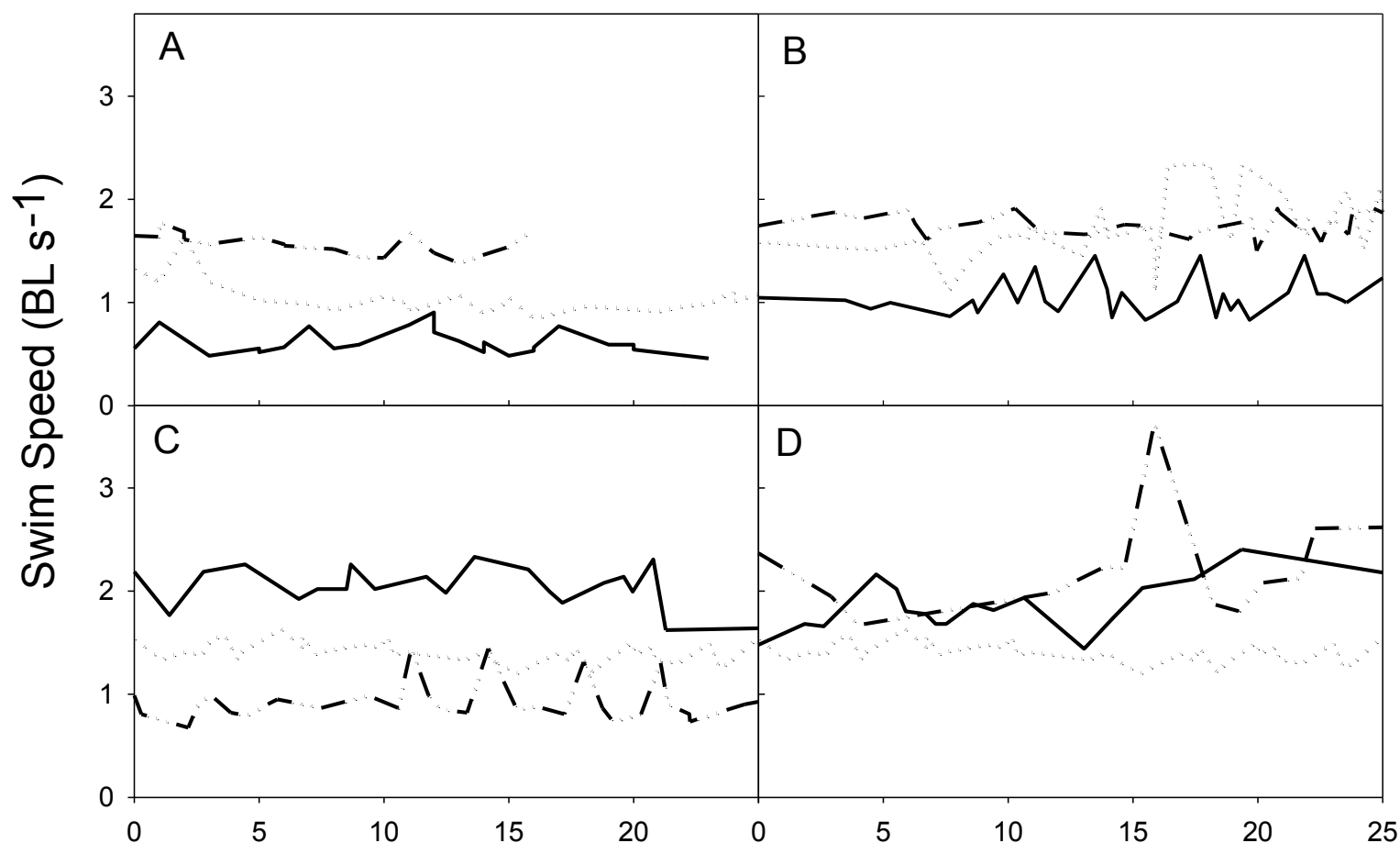

Duration (min)

Figure 3-4. Trace of swim speed for three individual sockeye salmon at A) Seymour Narrows, B) NSOG, C) River Entrance, and D) In River. Each line type represents a different individual. 


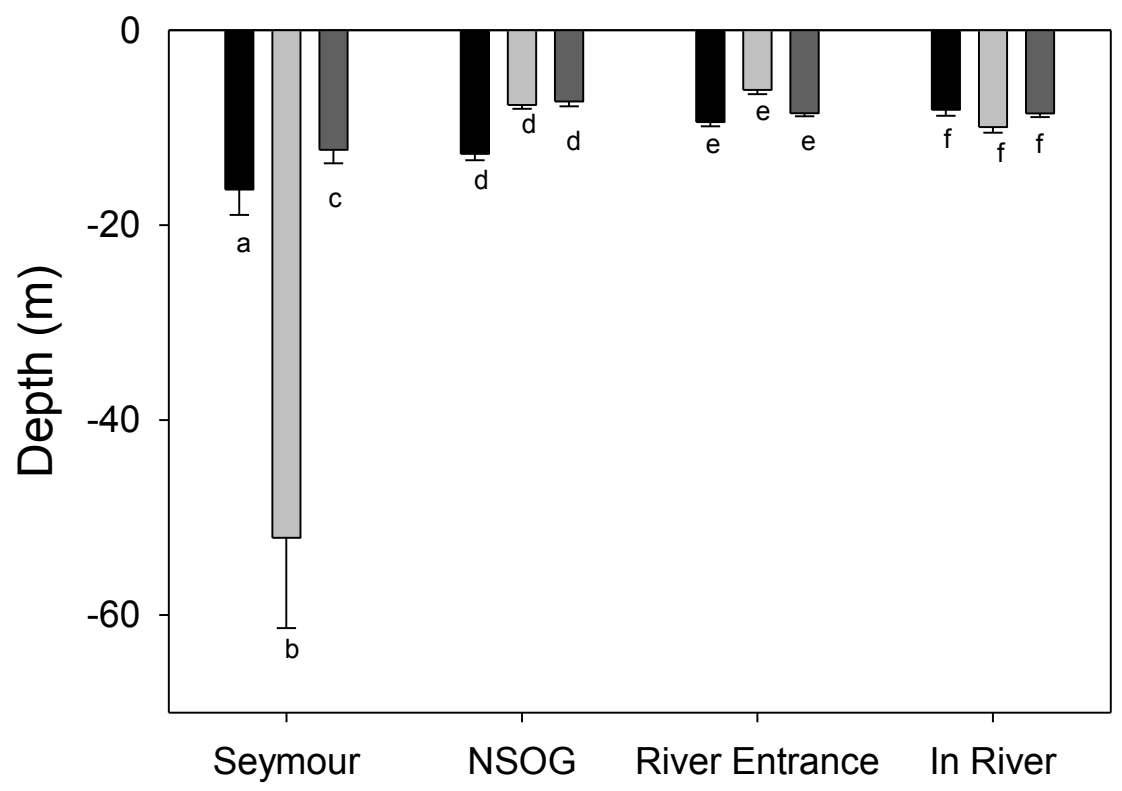

Figure 3-5. Depth of swimming for each migration index at each receiver array (see Fig. 4). Easy migrations are represented in black, intermediate in dark grey and difficult in light grey. Error bars represent SEM. Letters represent significant differences between migration difficulty groups $\alpha=0.05$. 


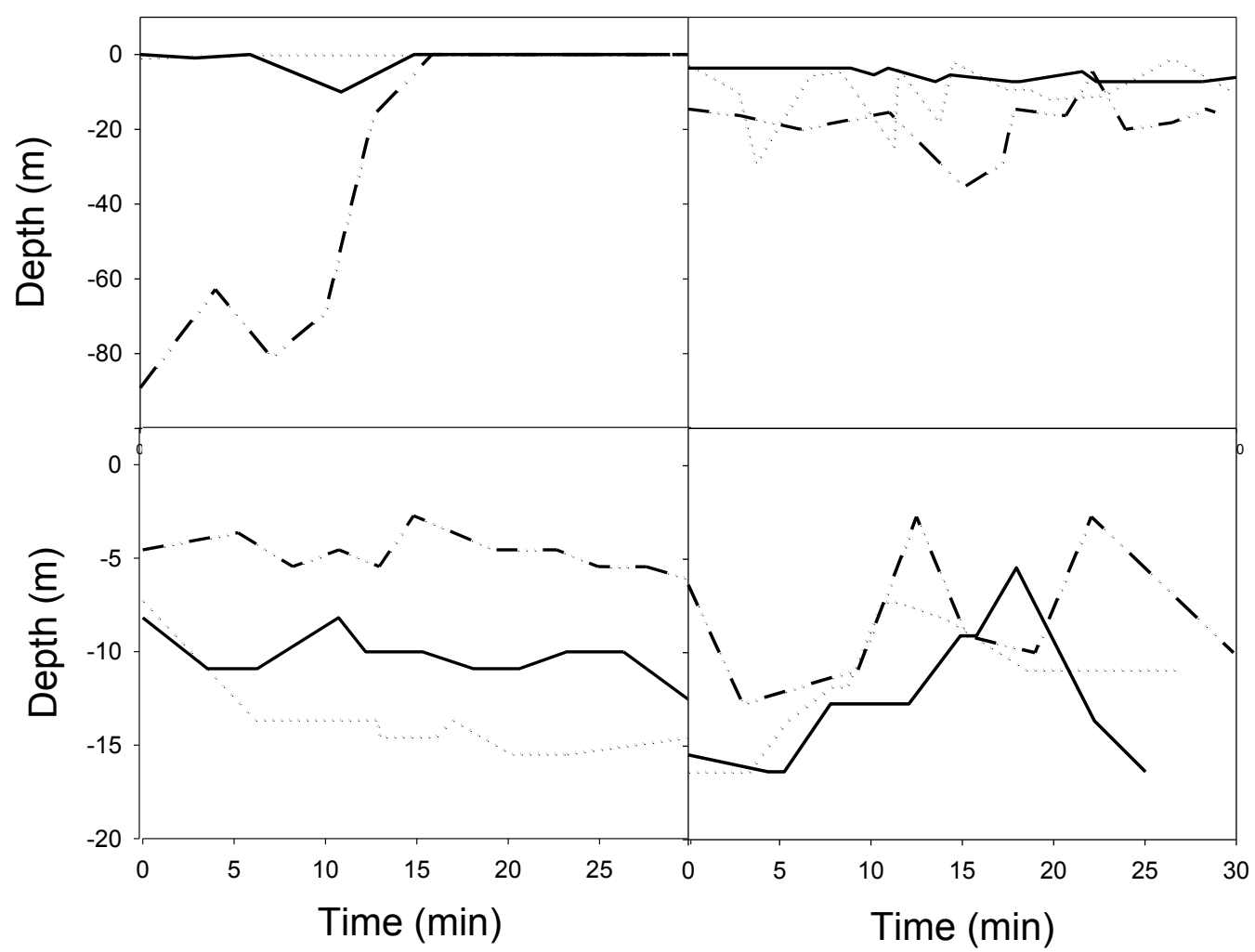

Figure 3-6. Trace of depth of swimming for three individual sockeye salmon at A) Seymour Narrows, B) NSOG, C) River Entrance, and D) In River. Each line type represents a different individual. 


\section{Chapter 4: General Discussion}

This dissertation assesses novel technology, acoustic acceleration transmitters, as a tool for estimating energy use and swimming behaviour of adult migrating sockeye salmon and uses the acceleration transmitter to characterize swim speed and depth use throughout the coastal migration route of adult sockeye salmon with unprecedented temporal resolution. In Chapter 2, adult sockeye salmon were tagged gastrically with an acceleration transmitter and placed in Brett-style swim tunnels to perform swim trials. TBF and accelerometer output from swim trials were used to verify that accelerometers accurately measure TBF. Models of swim speed and accelerometer output, as well as rate of oxygen consumption $\left(\mathrm{MO}_{2}\right)$ and accelerometer output were developed for use in predicting swim speed and $\dot{\mathrm{MO}}_{2}$ of free-swimming sockeye salmon. In Chapter 3, the acceleration transmitters were used to passively track adult sockeye salmon migration behaviour along marine coastal migration through the Strait of Georgia and lower Fraser River.

\section{Findings and Implications}

Sockeye salmon are one of the most studied migratory fish species in the world (Dingle, 1996; Hinch et al 2006; Dingle \& Drake, 2007). Despite this fact, much of the marine and coastal migration behaviour of sockeye salmon, and other Pacific salmon, remains a mystery. To date, studies of sockeye salmon migration behaviour have been limited to estimating segment-specific movement rates using mark-recapture techniques with a variety of tag types (Peterson disc, passive acoustic and radio telemetry), and 
assessing fine-scale continuous movements and rates using active acoustic telemetry in specific areas such as estuaries (Madison et al. 1972, Stasko et al. 1976, Quinn 1988). The development of novel acceleration transmitter technology has enabled the study of sockeye salmon migration swim speeds at a much higher resolution (once every $10 \mathrm{~s}$ compared to $15 \mathrm{~min})$, but the technology required laboratory validation and calibration prior to use in free swimming adult sockeye salmon. In Chapter 2, I verified that the acceleration transmitter, with a sampling frequency of $10 \mathrm{~Hz}$, reflected TBF. I found that acceleration and TBF had a positive and linear relationship $\left(0.55>\mathrm{R}^{2}<0.87\right.$; mean $=$ 0.81). Accelerations beyond $3.0 \mathrm{~m} \mathrm{~s}^{-2}$ failed to follow any relationship and were excluded from this thesis. Acceleration varied only slightly at a given swim speed, indicating that the accelerometer output successfully integrated aspects of locomotion beyond TBF that contribute to swim speed, such as tailbeat amplitude and other fine-scale differences in locomotion. I then developed statistical models to predict $\dot{\mathrm{MO}}{ }_{2}$ and swim speed from acceleration using mixed effect models. Acceleration $(\mathrm{p}<0.0001)$ was positively related to swim speed while fork length $(\mathrm{p}=0.051)$ was negatively related to swim speed. Rate of oxygen consumption and accelerometer output $(\mathrm{p}<0.0001)$ had a positive linear relationship and were temperature dependent $(\mathrm{p}<0.0001)$. The models of $\dot{\mathrm{MO}} 2$ and acceleration, and swim speed and acceleration can be used to generate empirically validated estimates of energy use and swim speed of migrating adult sockeye salmon using acoustic accelerometers. This work is the first to calibrate acoustic acceleration transmitters for measuring energy use in a vertebrate model species. 
In Chapter 3, I used the statistical model developed in Chapter 2 to estimate swim speed from acceleration output throughout coastal migration of gastric tagged, free swimming adult sockeye salmon. Measurement of swim speed using accelerometers supported conclusions found using mark-recapture and active acoustic tracking methods, and provided new insight into swim speed on a fine temporal scale. Additionally, diel period, tide, receiver location, as well as migration difficulty were found to be important predictors of swim speed. Swim speeds in the marine environment (Seymour Narrows and NSOG) were slower than in the river (marine 1.01 $\mathrm{BL} \mathrm{s}^{-1}$; Fraser River 1.54 BL s${ }^{-1}$; $\mathrm{p}<0.001$ ), supporting my prediction that river swim speed would increase in response to the increase in water velocity. Diel period was retained as an important predictor of swim speed, with fish swimming slightly faster during the day. This supports previous work which found that diel patterns in migration speed occurred, with individuals swimming faster during the day and more slowly at night, though the pattern in my study was not nearly as distinct as in Madison et al. (1972). Despite inclusion of environmental (location, diel period, and tide) as well as migration difficulty variables, much of the inter-individual variability remained unidentified. This variability may be due to physiological differences, as Spearman`s rank order correlation shows that fish swim consistently, where the fastest fish consistently swim fastest and the slowest fish were consistently the slowest. The swim speed estimates determined in this study were comparable to estimates of swim speed from other more traditional methods (i.e., acoustic, disc, radio) which show that sockeye salmon swim at $\sim 1 \mathrm{BL} \mathrm{s}^{-1}$ in the Strait of Georgia. However, use of measurements of swim speed from accelerometers yields more insight into swim speeds, individual variability, and population differences for a hitherto 
poorly described region (coastal transition zone). The increased resolution of these data adds to the knowledge base of sockeye salmon migration by highlighting the amount of inter-individual variability of swim speed and depth, much of which remains unexplained. This represents the first study to use accelerometer transmitters to measure swim speed in both the marine and freshwater environments for sockeye salmon.

\section{Future Directions}

Though only a small percent of fish species undertake migrations $(\sim 2.5 \%)$, migratory fish are an important resource, often being exploited by multiple user groups including commercial and recreational fishers (Hinch et al., 2006, Donaldson et al., 2011). Migratory species can be exploited at key locations as they are often predictable in both the timing of arrival and location. As a result, migratory fish species have been identified as being at higher risk for endangerment, where about twice as many migratory fish species are classified as 'threatened with extinction' compared with non-migratory species (Hinch et al., 2006). This risk is a exacerbated by anthropogenic challenges that may be encountered en-route (i.e., destruction of refugia, pollution, fishing pressure, altered flow regimes etc; Hinch et al., 2006; Donaldson et al., 2011). Thus understanding migration behaviour is critical to responsible fisheries management.

Acoustic acceleration transmitters may be particularly useful for fish species that have known migration routes, migrate long distances, where there is little chance of retrieving loggers, and are too small to attach pop-up satellite tags. Calibrations such as those performed in Chapter 2, should be completed on individuals of the same species and of similar year class (size), as species, and life history stage have been shown to 
effect routine and active metabolic rate and size, and morphology can influence locomotor performance and thus the swim speed-acceleration relationship. Tags should also be placed in the same place on each individual, and statistical tests should be performed to insure placement does not strongly influence the TBF-acceleration relationship (and thus other relationships), as in Chapter 2. If placement does influence acceleration, each tagged individual should be calibrated separately. Finally, adult migrating sockeye salmon are esociform and thunniform gait specialists, which means propulsion is more strongly derived from TBF (body/caudal fin; Webb, 1995). Chaetodontiform locomotor specialists utilize median and paired fin swimming more and thus have more complex accelerations. Accelerometer transmitters may not be useful for these fish, where RMS acceleration (averaging) may not be appropriate and $10 \mathrm{~Hz}$ sampling frequency may not be high enough to encompass very fast movements (Halsey et al., 2011). Regardless acceleration transmitter technology remains in its infancy, and improvements in sampling frequency and sampling algorithms are constantly being developed.

In Chapter 3, the average swim speed of sockeye salmon was determined to be $\sim 1 \mathrm{BL} \mathrm{s}^{-1}$ in the Strait of Georgia, consistent with other studies (Madison et al., 1972; Stasko et al., 1976; Quinn, 1988; Crossin et al., 2007). This is well within the optimal swim speed of sockeye salmon $\left(0.9-1.3 \mathrm{BL} \mathrm{s}^{-1}\right.$; Webb, 1995), where COT is lowest. Though location, diel period, tide and migration difficulty all explained some of the variability in swim speed, a large amount of inter-individual variability remains to be explained. Sockeye salmon are undergoing many complex processes during migration 
including changes in osmoregulation and sexual maturation. Differences in these states may influence swim speed, river entrance timing, river migration speed, arrival at spawning grounds and ultimately survival (Hinch \& Rand, 1998; Crossin et al., 2007; Crossin et al., 2009). Differences in physiology may further explain some of the variability in the data in Chapter 3, and should be examined in the future.

Finally, though the focus of this thesis is not on energetics, it is worth mentioning here that the data set collected in Chapter 3 may also be used to determine energy use and COT of coastal migrating sockeye salmon, given ambient water temperatures and the sex of the fish, and by applying saltwater tax (Wagner et al., 2006). Adult sockeye salmon cease feeding approximately $300 \mathrm{~km}$ from the mouth of the Fraser River, becoming reliant on endogenous energy stores for the remainder of their spawning migration. As a result, the bioenergetic budget for coastal migrating adult sockeye salmon is simplified, as salmon cease growing, energy intake becomes zero, and specific dynamic action associated with digestion is also negligible (reviewed in Brett et al., 1995). Thus the bioenergetic budget for adult migrating sockeye salmon is divided between reproductive maturation, somatic maintenance, and activity. Estimates of swim speed, or energy use from accelerometer output can be incorporated into these models to give us a better understanding of the portion of the bioenergetic budget used in activity. The potential to use this technology to help elucidate the relationship between environmental conditions (such as warming water temperatures) and energy use is possible and can aid in management forecast models. 
Overall, this thesis serves as a proof-of-principle for using acceleration transmitters (with a sampling frequency of $10 \mathrm{~Hz}$ ) to estimate swim speed and energy use in migrating fish species. Results presented in Chapter 2 show that the acceleration transmitters reflected TBF and could be used to estimate swim speed and energy use of adult sockeye salmon. This was further demonstrated in Chapter 3, where swim speed was estimated to be $\sim 1 \mathrm{BL} \mathrm{s}^{-1}$ in SOG, consistent with previous studies (Madison et al., 1972; Stasko et al., 1976; Quinn, 1988; Crossin et al., 2007). Differences in physiology may further explain some of the variability in the data in Chapter 3, and should be examined in the future. Given that migrating fish are at greater risk of endangerment, and that understanding their spatial ecology, and migration behaviours (especially swim speed), is critical to responsible fisheries management, acoustic acceleration transmitters may be of use in other migratory fishes, particularly those of ecological or economical importance or in species where long-term viability is in question. 


\section{Literature Cited}

Beacham, T.D., Withler, R.E. \& Wood, C.C. (1995). Stock identification of sockeye salmon by means of minisatellite DNA variation. North American Journal of Fisheries Management, 15, 249-265

Beacham, T.D., Lapointe, M., Candy, J.R., McIntosh, B., MacConnachie, C., Table, A., Kaukinen, K., Deng, L., Miller, K.M. \& Withler, R.E. (2004). Stock Identification of Fraser River sockeye salmon (Oncorhynchus nerka) using microsatellites and major histocompatibility complex variation. Transactions of the American Fisheries Society, 133, 1106-1126

Beamish, F.W.H. (1978). Swimming capacity. In Fish physiology, Vol 7. (eds W.S. Hoar, \& D.J. Randall), pp 101-189. Academic, New York

Beddow, T.A. \& McKinley, R.S. (1999). Importance of electrode positioning in biotelemetry studies estimating muscle activity in fish. Journal of Fish Biology, $54,819-831$

Brett, J.R. (1965). The relation of size to rate of oxygen consumption and sustained swimming speed of sockeye salmon (Oncorhynchus nerka). Journal of the Fisheries Research Board of Canada, 22, 1491-1501

Brett, J.R. (1995). Energetics. In Physiological ecology of Pacific salmon. (eds C. Groot, L. Margolis, \& W.C. Clarke), pp 3 - 68. University of British Columbia Press, Vancouver, B.C 
Brown, R.S., Tatara, C.P., Stephenson, J.R. \& Berejikian, B.A. (2007). Evaluation of a new coded electromyogram transmitter for studying swimming behavior and energetics in fish. North American Journal of Fisheries Management, 27, 765772

Brownscombe, J.W., Thiem, J.D., Hatry, C., Cull, F., Haak, C.R., Danylchuk, A.J., \& Cooke, S.J. (2013). Recovery bags reduce post-release impairments in locomotory activity and behaviour of bonefish (Albula spp.) following exposure to angling-related stressors. Journal of Experimental Marine Biology and Ecology, 440, 207-215

Burnham, K.P., \& Anderson, D.R. (2002). Model Selection and Multimodel Inference: A Practical Information-Theoretic Approach, 2nd edition. Springer, New York

Butler, P., Green, J., Boyd, I. \& Speakman, J. (2004). Measuring metabolic rate in the field: the pros and cons of the doubly-labelled water and heart rate methods. Functional Ecology, 18, 168-183

Calow, P. (1985). Adaptive aspects of energy allocation. In Fish Energetics: new perspectives (eds P. Tytler \& P. Calow), pp.13-31. Croom Helm, London

Clark, T.D., Sandblom, E., Hinch, S.G., Patterson, D.A., Frappell, P.B. \& Farrell, A.P. (2010). Simultaneous biologging of heart rate and acceleration, and their relationships with energy expenditure in free-swimming sockeye salmon (Oncorhynchus nerka). Journal of Comparative Physiology B, 180, 673-684 
Clark, T.D., Sandblom, E., Cox, G.K., Hinch, S.G. \& Farrell, A.P. (2008). Circulatory limits to oxygen supply during an acute temperature increase in the Chinook salmon (Oncorhynchus tshawytscha). American Journal of Physiology I, 295, $1631-1639$

Cook, R.C. \& Guthrie, I. (1987). In-season stock identification of sockeye salmon using scale pattern recognition. Canadian Special Publication of Fisheries and Aquatic Sciences, 96, 327-334.

Cooke, S.J., Hinch, S.G., Wikelski, M., Andrews, R.D., Wolcott, T.G. \& Butler, P.J. (2004a). Biotelemetry: a mechanistic approach to ecology. Trends in Ecology and Evolution, 19, 334-343

Cooke, S.J., Thorstad, E. \& Hinch, S.G. (2004b). Activity and energetics of freeswimming fish: insights from electromyogram telemetry. Fish and Fisheries, 5, $21-52$

Cooke, S.J., Crossin, G.T., Patterson, D.A., English, K.K, Hinch, S.G., Young, J.L., Alexander, R.F., Healey, M.C.,Van Der Kraak, G. \& Farrell, A.P. (2005). Coupling non-invasive physiological assessments with telemetry to understand inter-individual variation in behaviour and survivorship of sockeye salmon: development and validation of a technique. Journal of Fish Biology, 67, 13421358

Cooke, S.J., Hinch, S.G., Crossin, G.T., Patterson, D.A., English, K.K., Shrimpton, J.M., Van Der Kraak, G., \& Farrell, A.P. (2006). Physiology of individual late-run 
Fraser River sockeye salmon (Oncorhynchus nerka) sampled in the ocean correlates with fate during spawning migration. Canadian Journal Fisheries and Aquatic Science, 63, 1469-1480

Crossin, G.T., Hinch, S.G., Farrell, A.P., Higgs, D.A., Lotto, A.G., Oakes, J.D., \& Healey, M.C. (2004). Energetics and morphology of sockeye salmon: effects of upriver migratory distance and elevation. Journal Fish Biology, 65, 788-810

Crossin, G.T., Hinch, S.G., Cooke, S.J., Welch, D.W., Batten, S.D., Patterson, D.A., Van Der Kraak, G., Shrimpton, J.M., \& Farrell, A.P. (2007). Behaviour and physiology of sockeye salmon homing through coastal waters to a natal river. Marine Biology, 152, 905-918

Crossin, G.T., Hinch, S.G., Cooke, S.J., Cooperman, M.S., Patterson, D.A., Welch, D.W., Hanson, K.C., Olsson, I., English, K.K., \& Farrell, A.P. (2009). Mechanisms influencing the timing and success of reproductive migration in a capital breeding semelparous fish species, the sockeye salmon. Physiological and Biochemical Zoology, 82, 635-652

Davidsen, J.G., Rikardsen, A.H., Thorstad, E.B., Halttunen, E., Mitamura, H., Præbel, K., Skarðhamar, J., \& Næsje, T.F. (2013). Homing behaviour of Atlantic salmon (Salmo salar) during final phase of marine migration and river entry. Canadian Journal of Fisheries and Aquatic Science, In Press doi: 10.1139

Development Core Team (2011). R: A language and environment for statistical computing. R Foundation for Statistical Computing, Vienna, Austria. 
Dewar, H., Deffenbaugh, M., Thurmond, G., Lashkari, K., \& Block, B.A. (1999). Development of an acoustic telemetry tag for monitoring electromyograms in free-swimming fish. Journal of Experimental Biology, 202(19), 2693-2699

Dingle, H. (1980). Ecology and evolution of migration. In Animal migration, orientation, and navigation. (eds Gauthreaux, S.A. ) Academic Press: New York, NY.

Dingle, H. (1996). Migration: the biology of life on the move. Oxford University Press, Oxford

Dingle, H. \& Drake, V.A. (2007). What is migration? BioScience, 57(2), 113-121

Donaldson, M.R., O’Connor, C.M., Thompson, L.A., Gingerich, A.J., Danylchuk, S.E., Duplain, R.R., \& Cooke, S.J. (2011). Contrasting global game fish and nongame fish species. Fisheries, 36(8), 385-397

Drenner, S.M., Clark, T.D., Whitney, C.K., Martins, E.G., Cooke, S.J. \& Hinch, S.G. (2012). A synthesis of tagging studies examining the behaviour and survival of anadromous salmonids in marine environments. PLoS One, 7, e31311

Drenner, S. M., Martins, E.G., Hinch, S.G., Robichaud, D., Thompson, L.A., Patterson, D.A., Cooke, S.J. \& Thomson, R.E. Coastal Marine Thermal Experience of Homing Sockeye Salmon: Relationship with Physiology and Oceanography. Marine Ecology Progress Series, submitted 
Eliason, E.J., Clark, T.D., Hague, M.J., Hanson, L.M., Gallagher, Z.S., Jeffries, K.M., Gale, M.K., Patterson, D.A., Hinch, S.G. \& Farrell, A.P. (2011). Differences in thermal tolerance among sockeye salmon populations. Science, 332, 109-112

Eliason, E.J., Wilson, S.M., Farrell, A.P., Cooke, S.J. \& Hinch, S.G. (2013). Low cardiac and aerobic scope in a coastal population of sockeye salmon Oncorhynchus nerka with a short upriver migration. Journal of Fish Biology, 82, 2104-2112

Endler, J. A. (1977). Geographical variation, speciation and clines. Princeton University Press, Princeton, NJ.

English, K.K., Koski, W.R., Sliwinski, C., Blakley, A., Cass, A., \& Woodey, J.C. (2005). Migration Timing and River Survival of Late-Run Fraser River Sockeye Salmon Estimated Using Radiotelemetry Techniques. Transactions of the American Fisheries Society, 134, $1342-1365$

Fry, F.E.J. (1971). The effects of environmental factors on the physiology of fish. In Environmental relations and behaviors (eds W.S. Hoar \& D.J. Randall) Fish Physiology. Volume 6. Academic Press, New York.

Geist, D.R., Brown, R.S., Lepla, K. \& Chandler, J. (2002). Practical application of electromyogram radiotelemetry: the suitability of applying laboratory-acquired calibration data to field data North American Journal of Fisheries Management $22,474-479$ 
Gleiss, A., Dale, J., Holland, K. \& Wilson, R. (2010). Accelerating estimates of activity specific metabolic rate in fishes: Testing the applicability of acceleration data loggers. Journal of Experimental Marine Biology and Ecology, 385, 85-91

Green, J.A., Halsey, L.G., Wilson, R.P. \& Frappell, P.B. (2009). Estimating energy expenditure of animals using the accelerometry technique: activity, inactivity and comparison with the heart-rate technique. Journal of Experimental Biology, $212,471-482$

Halsey, L.G., Shepard, E.L.C., Quintana, F., Gomez Laich, A., Green, J.A. \& Wilson, R.P. (2009). The relationship between oxygen consumption and body acceleration in a range of species. Comparative Biochemistry and Physiology A, $152,197-202$

Halsey, L.G., Shepard, E.L.C., Hulston, C.J., Venables, M.C., White, C.R., Jeukendrup, A.E. \& Wilson, R.P. (2008). Acceleration versus heart rate for estimating energy expenditure and speed during locomotion in animals: tests with an easy model species, Homo sapiens. Zoology, 111, 231-241

Halsey, L.G., Shepard, E.L.C. \& Wilson, R.P. (2011). Assessing the development and application of the accelerometry technique for estimating energy expenditure. Comparative Biochemistry and Physiology A, 158, 305-314

Hanson, K.C., Cooke, S.J., Hinch, S.G., Crossin, G.T., Patterson, D.A., English, K.K., Donaldson, M.R., Shrimpton, J.M., Van Der Kraak, G., \& Farrell, A.P. (2008). Individual variation in migration speed of upriver migrating sockeye salmon in 
the Fraser River in relation to their physiological and energetic status at marine approach. Physiological and Biochemical Zoology, 81, 255-268

Heupel, M.R., Semmens, J.M., \& Hobday, A.J. (2006). Automated acoustic tracking of aquatic animals: scales, design and deployment of listening station arrays. Marine and Freshwater research, 57(1), 1-13

Hinch, S.G. \& Bratty, J. (2000). Effects of swim speed and activity pattern on success of adult sockeye salmon migration through an area of difficult passage. Transactions of the American Fisheries Society, 129, 598-606

Hinch, S.G., Cooke, S.J., Healey, M.C. \& Farrell, A.P. (2006). Behavioural physiology of fish migrations: salmon as a model approach. In Behaviour and Physiology of Fish (eds K.A. Sloman, R.W. Wilson, \& S. Balshine), Fish Physiology, 24, 239295

Hinch, S.G., Standen, E.M., Healey, M.C. \& Farrell, A.P. (2004). Swimming patterns and behaviour of upriver migrating adult pink (Oncorhynchus gorbuscha) and sockeye $(O$. nerka $)$ salmon as assessed by EMG telemetry in the Fraser River, British Columbia, Canada. Hydrobiologia, 165, 147-160

Hinch, S.G. \& Rand, P.S. (1998). Swim speeds and energy use of upriver-migrating sockeye salmon (Onchorhynchus nerka): role of local environment and fish characteristics. Canadian Journal of Fisheries and Aquatic Science, 55, 18211831 
Hinch, S.G., \& Rand, P.S. (2000). Optimal swim speeds and forward assisted propulsion: energy conserving behaviours of up-river migrating salmon. Canadian Journal of Fisheries and Aquatic Science, 57, 2470-2478

Holland, K.N., Brill, R., Ferguson, S., Chang, R., \& Yost, R. (1985). A small vessel technique for tracking pelagic fish. U.S. National Marine Fisheries Service Marine Fisheries Review 47(4), 26-32

Holland, K.N., Lowe, C.G., Peterson, J.D., \& Gill, A. (1992). Tracking coastal sharks with small boats: hammerhead shark pups as a case-study. Australian Journal of Marine and Freshwater Science 43 , 61-66

Hothorn, T., Bretz, F., \& Westfall, P. (2008). Simultaneous Inference in General Parametric Models. Biometrical Journal, 50(3), 346 - 363

Jain, K.E., Hamilton, J.C. \& Farrell, A.P. (1997). Use of a ramp velocity test to measure critical swimming speed in rainbow trout, Oncorhynchus mykiss. Comparative Biochemistry and Physiology A, 117, 441-444

Jones, D.R., Kiceniuk, J.W. \& Bamford, O.S. (1974). Evaluation of the swimming performance of several fish species from the Mackenzie River. Journal of Fisheries Research Board of Canada, 31, 1641-1647

Jönsson, K. I. (1997). Capital and income breeding as alternative tactics of resource use in reproduction. $O I K O S, 78,57-66$ 
Kawabe, R., Kawano, T., Nakano, N., Yamashita, N., Hiraishi, T., \& Naito, Y. (2003). Simultaneous measurement of swimming speed and tail beat activity of freeswimming rainbow trout Oncorhynchus mykiss using an acceleration datalogger. Fisheries Science, 69, 959-965

Lee, C.G., Farrell, A.P., Lotto, A., MacNutt, M.J., Hinch, S.G. \& Healey, M.C. (2003). The effect of temperature on swimming performance and oxygen consumption in adult sockeye (Oncorhynchus nerka) and coho (O. kisutch) salmon stocks. Journal of Experimental Biology, 206, 3239-3251

Lembo, G., Carbonara, P., Scolamacchia, M., Spedicato, M.T., Bjørnsen, J.E., Holand, B. \& McKinley, S. (2008). Introduction of a new physiological acoustic electromyogram transmitter. Fisheries Management and Ecology, 15, 333-338

Levy, D.A., \& Cadenhead, A.D. (1995). Selective tidal stream transport of adult sockeye salmon (Oncorhynchus nerka) in the Fraser-River estuary. Canadian Journal of Fisheries and Aquatic Science, 52, 1-12

Lowe, C.G., Holland, K.N. \& Wolcott, T.G. (1998). A new acoustic tailbeat transmitter for fishes. Fisheries Research, 36, 275-283

MacNutt, M.J., Hinch, S.G., Lee, C.G., Phibbs, J.R., Lotto, A.G., Healey, M.C. \& Farrell, A.P. (2006). Temperature effects on swimming performance, energetics, and aerobic capacities of mature adult pink salmon (Oncorhynchus gorbuscha) compared with those of sockeye salmon (Oncorhynchus nerka). Canadian Journal of Zoology, 84, 88-97 
Madison, D.M., Horrall, R.M., Stasko, A.B., \& Hasler, A.D. (1972). Migratory movements of adult sockeye salmon (Oncorhynchus nerka) in coastal British Columbia as revealed by ultrasonic tracking. Journal of Fisheries Research Board of Canada, 29, 1025-1033

Martins, E.G., Hinch, S.G., Cooke, S.J., \& Patterson, D.A. (2012). Climate effects on growth, phenology, and survival of sockeye salmon (Oncorhynchus nerka): a synthesis of the current state of knowledge and future research directions. Reviews in Fisheries Biology, 22, 887-914

Mathes, M.T., Hinch, S.G., Cooke, S.J., Crossin, G.T., Patterson, D.A., Lotto, A.G., \& Farrell, A.P. (2010). Effect of water temperature, timing, physiological condition and lake thermal refugia on migrating adult Weaver Creek sockeye salmon (Oncorhynchus nerka). . Canadian Journal of Fisheries and Aquatic Science, $67,70-84$

Mazerolle, M.J. (2012) AICcmodavg: Model selection and multimodel inference based on (Q) AIC(c). R package version 1.25.

McDowall, R.M. (1988). Diadromy in fishes: migrations between freshwater and marine environments. Croom-Helm, London.

McDowall, R.M. (1999). Different kinds of diadromy: different kinds of conservation problems. ICES Journal of Marine Science 56, 410- 413 
McMaster, M., Munkittrick, K. \& Van Der Kraak, G. (1992). Protocol for measuring circulating levels of gonadal sex steroids in fish. Canadian Technical Reports of Fisheries and Aquatic Sciences, 1836, 1-29

McNamara, J.M. \& Houston, A.I. (1996). State-dependent life histories. Nature, 380, $215-221$

Meyer, C.G. \& Holland, K.N. (2001). A kayak method for tracking fish in very shallow water. In Electronic tagging and tracking in marine fisheries. Reviews: Methods and technologies in fish biology and fisheries, vol 1. (eds, Silbert, J.R. \& Nielsen, J.) pp 289 - 296. Kluwer Academic Publishers, Dordrecht, Netherlands.

Miller, K.M., Schulze, A.D., Ginther, N., Li, S., Patterson, D.A., Farrell, A.P., \& Hinch, S.G. (2009). Salmon spawning migration: Metabolic shifts and environmental triggers. Comparative Biochemistry and Physiology D, 4, 75-89

Murchie, K.J., Cooke, S.J., Danylchuk, A.J. \& Suski, C.D. (2011). Estimates of field activity and metabolic rates of bonefish (Albula vulpes) in coastal marine habitats using acoustic tri-axial accelerometer transmitters and intermittent-flow respirometry. Journal of Experimental Marine Biology and Ecology, 396, 147155

Nagy, K.A. \& Costa, D.P. (1980). Water flux in animals: analysis of potential errors in the tritiated water method. American Journal of Physiology I, 238, R454-R465 
Newell, J.C. \&, Quinn, T.P. (2005). Behavioral thermoregulation by maturing adult sockeye salmon (Oncorhynchus nerka) in a stratified lake prior to spawning. Canadian Journal of Zoology, 83, 1232-1239

Ogura, M., \& Ishida, Y. (1995). Homing behavior and vertical movements of four species of Pacific salmon (Oncorhynchus spp.) in the Central Bering Sea. Canadian Journal of Fisheries and Aquatic Science, 52, 532-540

O’Toole, A.C., Murchie, K.J., Pullen, C., Hanson, K.C., Suski, C.D., Danylchuk, A.J. \& Cooke, S.J. (2010). Locomotory activity and depth distribution of adult great barracuda (Sphyraena barracuda) in Bahamian coastal habitats determined using acceleration and pressure biotelemetry transmitters. Marine and Freshwater Research, 61, 1446-1456

Patterson, D.A., Macdonald, J.S., Skibo, K.M., Barnes, D.P., Guthrie, I. \& Hills, J. (2007). Reconstructing the summer thermal history for the lower Fraser River, 1941 to 2006, and implications for adult sockeye salmon (Oncorhynchus nerka) spawning migration. Canadian Technical Reports of Fisheries and Aquatic Sciences, 2724, 1

Payne, N.L., Gillanders, B.M., Seymour, R.S., Webber, D.M., Snelling, E.P. \& Semmens, J.M. (2011). Accelerometry estimates field metabolic rate in giant Australian cuttlefish Sepia apama during breeding. Journal of Animal Ecology, $80,422-430$ 
Pinheiro, J., Bates, D., DebRoy, S., Sarkar, D., R Development Core Team (2013). Linear and Nonlinear Mixed Effects Models. R package version 3.1-108

Quinn, T.P. (1988). Estimated swimming speeds of migrating adult sockeye salmon. Canadian Journal of Zoology, 66, 2160-2163

Quinn, T.P., Terhart, B.A. \& Groot, C. (1989). Migratory orientation and vertical movements of homing adult sockeye salmon, Oncorhynchus nerka, in coastal waters. Animal Behaviour, 37, 587-599

Rand, P.S. \& Hinch, S.G. (1998). Swim speeds and energy use of upriver-migrating sockeye salmon (Onchorhynchus nerka): simulating metabolic power and assessing risk of energy depletion. Canadian Journal of Fisheries and Aquatic Science, 55, 1832-1841

Roscoe, D.W., Hinch, S.G., Cooke, S.J., \& Patterson, D.A. (2010). Behaviour and thermal experience of adult sockeye salmon migrating through stratified lakes near spawning grounds: the roles of reproductive and energetic states. Ecology of Freshwater Fish, 19, 51-62

Scharold, J. \& Gruber, S.H. (1991). Telemetered heart-rate as a measure of metabolicrate in the lemon shark, Negaprion-Brevirostris. Copeia, 4, 942-953

Shepard, E.L.C., Wilson, R.P., Quintana, F., Gomez-Laich, A., Liebsch, N., Albareda, D.A., Halsey, L.G., Gleiss, A., Morgan, D.T., Myers, A.E., Newman, C. \& 
Macdonald, D.W. (2008). Identification of animal movement patterns using triaxial accelerometry. Endangered Species Research, 10, 47-60

Sugiura, N. (1978). Further analysis of the data by Akaike's information criterion and the finite corrections. Communications in Statistics A, 7, 13-26

Standen, E.M., Hinch, S.G., \& Rand, P.S. (2004). Influence of river currents on path selection and swimming efficiency of migrating adult sockeye salmon. Canadian Journal of Fisheries and Aquatic Sciences 61, 905-912

Stasko, A.B., Horrall, R.M., \& Hasler, A.D. (1976). Coastal movements of adult Fraser River sockeye salmon (Oncorhynchus nerka) observed by ultrasonic tracking. Transactions of the American Fisheries Society, 105, 64-71

Thorarensen, H., Gallaugher, P.E. \& Farrell, A.P. (1996). The limitations of heart rate as a predictor of metabolic rate in fish. Journal of Fish Biology, 49, 226-236

Tucker, V.A. (1970). Energetic cost of locomotion in animals. Comparative Biochemistry and Physiology, 34, 841-846

Ueda, H., Urano, A, Zohar, Y., \& Yamauchi, K. (2000). In Hormonal control of homing migration in salmonid fishes. Proceedings of the $6^{\text {th }}$ international symposium on the reproductive physiology of fish. $p p 95-98$. Department of fisheries and marine biology, University of Bergen, Bergen, Norway.

Wagner, G.N., Kuchel, L.J., Lotto, A., Patterson, D.A., Shrimpton, J.M., Hinch, S.G. \& Farrell, A.P. (2006). Routine and active metabolic rates of migrating adult wild 
sockeye salmon (Oncorhynchus nerka walbaum) in seawater and freshwater. Physiological and Biochemical Zoology, 79, 100-108

Webb, P.W. (1984). Form and function in fish swimming. Scientific American 251, 72 82

Webb, P.W. (1995). Locomotion. In Physiological ecology of Pacific salmon. (eds C. Groot, L. Margolis, \& W.C. Clarke), pp 69 - 101. University of British Columbia Press, Vancouver, B.C

Welch, D.W., Melnychuk, M.C., Payne, J.C., Rechisky, E.L., Porter, A.D., Jackson, G., Ward, B., Vincent, S., Wood, C.C., \& Semmens, J. (2011). In situ Measurement of Coastal Ocean Movements and Survival of Juvenile Pacific Salmon. Proceedings of the National Academy of Science USA, 108, 8708 - 8713

Wilson, R.P., White, C.R., Quintana, F., Halsey, L.G., Liebsch, N., Martin, G.R. \& Butler, P.J. (2006). Moving towards acceleration for estimates of activityspecific metabolic rate in free-living animals: the case of the cormorant. Journal of Animal Ecology, 75, 1081-1090

Wilson, S.M., Hinch, S.G., Eliason, E.J., Farrell, A.P., \& Cooke, S.J. (2013). Calibrating acoustic acceleration transmitters for estimating energy use by wild adult Pacific salmon. Comparative Biochemistry and Physiology A, 164(3), 491-498 